\title{
Pilot scale anion selectrodialysis for water reclamation and nutrient recovery from UASB effluent after nitrification, ultrafiltration and UV C treatment
}

\author{
Boudewijn Meesschaert $^{\mathrm{a}, *}$, Karel Ghyselbrecht ${ }^{\mathrm{a}}$, Annick Monballiu ${ }^{\mathrm{a}}$, Luc Pinoy ${ }^{\mathrm{b}}$ \\ a Department of Microbial and Molecular Systems, Faculty of Engineering Technology, KU Leuven Bruges Campus, Spoorwegstraat 12, B-8200 Brugge, Belgium \\ b Department of Chemical Engineering, Faculty of Engineering Technology, KU Leuven Ghent Technology Campus, Gebroeders De Smetstraat 1, B-9000 Gent, Belgium
}

\section{A R T I C L E INF O}

\section{Article history:}

Received 29 December 2020

Received in revised form 24 February 2021

Accepted 25 February 2021

Available online $\mathrm{xxx}$

\section{Keywords:}

Fractionation

Phosphate

Anion selectrodialysis

Nutrient recovery

\begin{abstract}
A B S T R A C T
In the frame of the increasing need of nutrient recovery and recycling the objective was to fractionate and concentrate nutrients from nitrified, ultra-filtered and ultraviolet C treated UASB effluent with anion selectrodialysis (aSED). Under these conditions it was possible to keep the system in operation for 14 days or even for 3 weeks with intermittent cleaning in place every week. When membranes developed in the frame of sulphuric acid production (PC-Acid 100 OT) were used as anion exchange membranes (AE membranes) instead of standard AE membranes (PC-SA) a 4.5 times higher current efficiency for phosphate transport was noted. The diluate of the aSED is reusable as e.g. cooling water for condensers. The product stream which is enriched in phosphate $\left(5-6 \mathrm{mmol} \mathrm{L}^{-1}\right)$ and the brine stream which accumulated potassium $\left(150 \mathrm{mmol} \mathrm{L}^{-1}\right)$ and nitrate $\left(90 \mathrm{mmol} \mathrm{L}^{-1}\right)$ are suitable for nutrient recovery. During the optimization process the current efficiency for phosphate transport increased tenfold, from $0.7 \%$ to $7 \%$. The product stream was fed to a lamella separator (with a molar $\mathrm{Ca} / \mathrm{P}$ ratio of \pm 1.93 ) to recover $98 \%$ of the phosphate. The recovered precipitate was free of magnesium and contained the equivalent of 30 to $38 \mathrm{~m} \% \mathrm{P}_{2} \mathrm{O}_{5}$; $\mathrm{XRD}$ analysis showed the presence of hydroxyapatite. The $\mathrm{Ca} / \mathrm{P}$ ratio of this precipitate decreased proportionally with the degree of aeration to expel dissolved inorganic carbon from the feed to the aSED, indicating less coprecipitation of calcium carbonate within the recovered calcium phosphate.
\end{abstract}

\section{Introduction}

Three-component fertilizers contain nitrogen $(\mathrm{N})$, phosphorus $(\mathrm{P})$ and potassium $(\mathrm{K})$. These nutrients are essential for life on earth and agriculture. However, high concentrations of $\mathrm{N}$ and $\mathrm{P}$ in the effluents of wastewater treatment systems also lead to eutrophication problems. Consequently, these elements should be removed from these effluents, which thus must comply with increasingly stringent discharge limits.

Despite a downward trend in developed regions, the demand for phosphorus is increasing globally. This is due to an increase in the overall demand for food and global trends towards the consumption of more meat- and dairy based diets, which are P intensive (Heffer and Prud'homme, 2009). Several factors such as the price of phosphate rock, the world population growth, the demand for food and the amount of phosphate rock reserves determine the date when easily accessible phosphate rock will be depleted; all studies assume that this will occur within 50 to 250 years (Gunther, 1997; Cisse and Mrabet, 2004; Van Vuuren et al., 2010; Desmidt et al., 2015). Biochemically there is no substitute for $\mathrm{P}$ and therefore the mentioned removal of $\mathrm{P}$ from wastewater to comply with discharge limits should go hand in hand with recovery of the removed phosphorus (Cordell et al., 2000).

Like $\mathrm{P}, \mathrm{K}$ is a fertilizer that is extracted from sediments. And although the situation for $\mathrm{K}$ is not so dramatical as for $\mathrm{P}$, also its reserves are limited. Predictions assume that supply problems with $\mathrm{K}$ will start in about 400 years (Yakovleva, 2017).

The situation with $\mathrm{N}$ is completely different. $78 \mathrm{vol} \%$ of the air consists out of nitrogen gas and the Haber-Bosch process can supply all the ammoniacal nitrogen that is needed in agriculture. The nitrogen cycle is however energy consuming, has thus a high carbon foodprint and consequently is not sustainable. In short: after its energy consuming synthesis, ammonium is partially oxidized to

* Corresponding author.

E-mail address: boudewijn.meesschaert@kuleuven.be (B. Meesschaert) 
nitrate and the resulting ammonium nitrate is used as fertilizer. Within the crops the $\mathrm{N}$ from fertilizers is built into proteins. After human or animal consumption part of this proteinogenic $\mathrm{N}$ ends up as urea in wastewater where it hydrolyses to ammonium and bicarbonate (Fields, 2004). In pre-Haber-Bosch times human and animal excrements were nearly the only N fertilizers. On the contrary, ammoniacal $\mathrm{N}$ that ends up nowadays in wastewater is - at the expense of large amounts of energy - first nitrified to nitrate and subsequently denitrified to nitrogen gas, the starting product of the nitrogen cycle. It is evident that a more sustainable use of $\mathrm{N}$ is required, e.g. by recovering ammonium or nitrate from wastewater.

Phosphorus recovery from industrial and municipal wastewaters has drawn much attention of the water and phosphorous industry in recent years (Driver et al., 1999; Schipper et al., 2001; Roeleveld et al., 2004). Basically, two ways for recovering P exists: P is either recovered directly from the wastewater or it is incorporated in the sludge and recovered from the latter after incineration (Desmidt et al., 2015). For the recovery of $P$ from wastewater the water is first anaerobically treated, e.g. in the frame of energy recuperation as biogas. The phosphate rich anaerobic effluent is then fed into a precipitation/crystallization tank, which is either mixed or in fluidized state. Calcium or magnesium salts and - where needed - seed crystals are added to recover phosphate as calcium phosphate $\left(\mathrm{Ca}_{3}\left(\mathrm{PO}_{4}\right)_{2}\right.$, hydroxyapatite $\left(\mathrm{Ca}_{5}\left(\mathrm{PO}_{4}\right)_{3} \mathrm{OH}\right)$ or struvite $\left(\mathrm{MgNH}_{4} \mathrm{PO}_{4} \cdot 6 \mathrm{H}_{2} \mathrm{O}\right)$. However, it is known that efficient phosphate precipitation and crystallization (e.g. as struvite) are only possible if the wastewater contains a $\mathrm{PO}_{4}^{3-}$-P concentration of at least $40 \mathrm{mg} \mathrm{L} \mathrm{L}^{-1}(\mathrm{Jaffer}$ et al., 2002). If the concentration is lower, it is appropriate to concentrate the phosphate prior to this precipitation step, e.g. by electrodialysis (Hell et al., 1998).

Much energy has been put into the development of methods for the recovery of phosphate as struvite (Desmidt et al., 2015). Struvite, as slow releasing fertilizer, for sure has its potential in agriculture. Many regions in Western Europe have however large phosphate concentrations in the soil as a result of years of overfertilization with e.g. manure and the further use of phosphate fertilizer is forbidden or largely restricted. In this specific context the recovery of phosphate as a fertilizer is not an obvious option and the local commercial value of struvite is low. An alternative can then be found in the recovery of phosphate as calcium phosphate. The latter can be added to phosphorous ore, which roughly has the same chemical composition and thus can be put to value in the phosphorous industry (Desmidt et al., 2015). The resulting phosphate containing fertilizer can then be commercialized worldwide.

Electrodialysis (ED) is an emerging electrochemical membrane process in which salt ions are transported from one aqueous solution (the feed; which gets depleted of ions and becomes the diluate) through ion-exchange membranes to another aqueous solution (the brine, enrichment of ions) under the influence of an applied electrical potential difference (Hell et al., 1998). In contrast to reverse osmosis (RO), ED is thus not a pressure driven separation process. Traditional ED has been widely used for the desalination of brackish water and seawater because of its high concentration potential, low operation pressure and lower fouling potential (Strathmann, 2010; Zhang et al., 2017; Liu et al., 2016). More recently, ED is also been used in the context of nutrient recovery from wastewaters, more specifically in the frame of concentrating nutrient ions, e.g. of phosphate ions before they can be precipitated e.g. as struvite (Zhang et al., 2013) or as calcium phosphate (Tran et al., 2014). Lab scale ED was successfully used to concentrate $\mathrm{NH}_{4}^{+}-\mathrm{N}, \mathrm{PO}_{4}^{3-}-\mathrm{P}$ and $\mathrm{K}+(\mathrm{Pronk}$ et al., 2006; Mehta et al., 2015). Ward et al. (2018) demonstrated the feasibility of nutrient recovery $\left(\mathrm{NH}_{4}^{+}-\mathrm{N}\right.$ and $\left.\mathrm{K}+\right)$ from domestic anaerobic digester supernatant through pilot scale ED.

Although much research has been done into the applicability of ED, little is known about the separation and concentration of nutrients with the same charge (e.g. $\mathrm{NO}_{3}^{-}$and $\mathrm{HPO}_{4}^{2-}$ ) from wastewater. In this context, a novel electrodialysis configuration, denoted as anion selectrodialysis (aSED) was developed, in which the electrodialysis stack was equipped with a combination of standard anion-exchange membranes and monovalent selective anion-exchange membranes (Zhang et al., 2012). Monovalent selective anion selective membranes are designed to retain multivalent anions. The most common way is to add a negatively charged layer on the positively charged backbone of the membrane. This extra negative layer repels the multivalent ions (Tran et al., 2015). When compared to standard ED, in aSED, instead of one, two circulating concentrate streams exist, one with the multivalent anions, further referred to as the product (stream), and one with the monovalent anions, further referred to as the brine (stream). The initially developed aSED stack is thus capable to desalinate a stream while simultaneously fractionating between multivalent ions such as sulphate and phosphate and monovalent anions, such as chloride and nitrate (Zhang et al., 2012; Tran et al., 2015). A combination of two electrical potential-driven ion-exchange membrane technologies, namely aSED and bipolar membrane electrodialysis (BMED), was successfully used for the valorization of chemical industry process brines (containing $\mathrm{NaCl}$ and $\mathrm{Na}_{2} \mathrm{SO}_{4}$ ) (Reig et al., 2016). More recently, Liu et al. (2017) examined the treatment of a synthetically simulated secondary effluent with aSED on lab scale. It was found that the aSED technology had the capability to concentrate nutrients (nitrate in the brine and phosphate in the product) and simultaneously to realize zero liquid discharge of secondary wastewaters.

The wastewater of potato-processing plants contains high concentrations of inorganic and organic carbon, phosphate, potassium and nitrogen (Meesschaert et al., 2020). The peeling and cutting of potatoes cause cell damage and large quantities of starch are set free during these processes and end up in the wastewater. Although most of the starch is recovered and sold to other industries, the biochemical oxygen demand (BOD) of the wastewater stays high enough to justify an anaerobic treatment in an upflow anaerobic sludge blanket reactor (UASB) with or without biogas recuperation. Peculiar to this anaerobic pretreatment is the mineralization of organic compounds. Phosphate is liberated from nucleic acids and polyphosphates and ammonium is set free from proteins. The phosphate further originates from the addition of pyrophosphates to prevent discolouration of the potatoes during their processing and preservation. Characteristic for the UASB effluents is further their high concentration of potassium and high bicarbonate alkalinity or high concentration of dissolved inorganic carbon (DIC) (Meesschaert et al., 2020).

In a procedure to recover phosphate from UASB effluents as calcium phosphate, Monballiu et al. (2018a, b) introduced a nitrification as pre-treatment. The latter consumes the double equivalent amount of DIC and facilitates phosphate recovery since inhibition by bicarbonate is avoided and competitive precipitation of calcium carbonate is greatly reduced. Formation of calcium carbonate is also the reason for scaling of membranes in electrodialysis processes (Zhang et al., 2011) and hence, a preceding nitrification of the 
feed with the accompanying consumption of DIC should facilitate electrodialysis processes. In addition, the nitrification reaction results in the net removal of anions since two DIC's are consumed and only one nitrate is formed. This should be beneficial for the current efficiency for phosphate removal since the relative contribution of the negative charges of .phosphate (actually $\mathrm{HPO}_{4}^{2-}$ ) in current transmission is increasing. Furthermore, it was observed that the rather large monovalent charged bicarbonate ions also accumulated in the product stream during aSED (Zhang et al., 2013; Ghyselbrecht et al., 2020). The observation that DIC accumulated in the phosphate containing product stream during aSED was a supplementary reason to implement a nitrification on the UASB effluent as pre-treatment for aSED separations. In summary, the nitrification as pre-treatment will lead to lower DIC concentrations in the feed and in the product and should improve phosphate mobility during selectrodialysis and phosphate recovery from the product (Meesschaert et al., 2020; Monballiu et al., 2018a).

The nitrification of the UASB effluent results in the conversion of endogenous ammonium to nitrate. In contrast to ammonium which can became volatile as ammonia at higher $\mathrm{pH}$ values $\left(\mathrm{pK}_{\mathrm{a}}=9.2\right)$, nitrate is stable in aqueous solutions. In addition, the UASB effluent contains phosphate-P and potassium (Meesschaert et al., 2020). This pre-treatment thus results in type of wastewater that is highly suited for research on nutrient (NPK) fractionation and concentration by means of aSED.

The final goal of this study on UASB effluent is to investigate how long an aSED can be kept in operation as method for fractionation and preconcentration of phosphate in the product and of nitrate and potassium in the brine. Secondly, it is the aim to recover the phosphate from the product as calcium phosphate and to investigate how the expected contamination with calcium carbonate can be reduced. This work relies on and continues previous work on the recovery of phosphate as calcium phosphate (Meesschaert et al., 2020; Monballiu et al., 2018a,b) and the fractionation and concentration of phosphate from UASB effluent with aSED (Zhang et al., 2013, 2012; Ghyselbrecht et al., 2020). In batch modus both on lab and pilot scale, the use of PC-Acid 100 OT instead of PC-SA membranes (both from PCA) as standard anion-exchange resulted in a higher phosphate-P concentration in the product stream (Ghyselbrecht et al., 2020). At first, the continuous application of aSED at pilot scale was tested in the feed and bleed mode with PC-SA membranes from PCA as standard anion exchange membranes (Zhang et al., 2013, 2012). In the following experiment, it was investigated if the positive result with PC-Acid 100 OT membranes as standard anion-exchange membranes can be confirmed in long-term feed and bleed tests. The phosphate that accumulated in the product stream was recovered in a lamella separator by the addition of $\mathrm{CaCl}_{2}$. It was further also investigated if intermittent cleaning in place (CIP) of the diluate circuit of the aSED could extend operation time and if extra aeration of the feed of the aSED to expel carbon dioxide has a positive effect on ionic transport and the purity of the calcium phosphate that can be recovered from the lamella separator.

\section{Materials and methods}

\subsection{Origin of the nitrified effluent}

All USAB effluent used in this study was from the Wielsbeke plant of Agristo, a Belgian potato processor and was subjected to a pre-settling step in two combined international bulk containers (IBC) as described previously (Meesschaert et al., 2020; Ghyselbrecht et al., 2020). The equipment was part of the one used to recover phosphate directly from UASB effluent without preconcentration with aSED (Meesschaert et al., 2020). The hydraulic retention time (HRT) in the feeding IBC to the nitrification reactor was $15 \mathrm{~h}$. Compressed air was supplied to the nitrification reactor and the flow rate of pre-settled UASB effluent was monitored to obtain full nitrification; the HRT was about 1day. The effluent was sent to an UF-filter (for the details see Meesschaert et al., 2020; Ghyselbrecht et al., 2020) and both the feed and the filtrate were recirculated over a $60 \mu \mathrm{m}$ cartridge filter and a UV-C lamp (Clean Pond UV-C 18 Watt) with an aquarium recirculation pump (Newa NJ 1700) to reduce the amount of suspended solids and to minimize microbial growth (Venugopalan, 2015). The backwash (30 s $1200 \mathrm{~L} \mathrm{~h}^{-1}$ ) during Experiments 1 and 2 was sent back to the nitrification reactor, but in Experiment 3 it was sent back to the wastewater treatment of the plant. Fig. 1 shows the implemented pretreatment steps to produce suitable feed water for the aSED pilot installation.

\subsection{Anion selectrodialysis equipment and membrane configurations used}

An EDQ 380 (PCCell GmbH, Heusweiler, Germany) pilot scale stack was inserted in a pilot scale plant assembled by I.E.C. NV (Riemst, Belgium). Details are presented in Ghyselbrecht et al. (2013). In short, the setup consisted of four $200 \mathrm{~L}$ vessels for the diluate, product, brine and the electrode rinsing solution (ERS). Monovalent selective anion-exchange membranes (PC-MVA), standard cation-exchange membranes (PC-SC), end cation-exchange membranes (PC-SK; mounted against the electrodes) and standard anion-exchange membranes (either PC-SA or PC-Acid 100 OT) were installed in the pilot scale stack; the stack consisted of 20 cell triplets. All the membranes mentioned were supplied by PCA — PolymerChemie Altmeier GmbH, Heusweiler, Germany; some characteristics, obtained them from the manufacturer, are given in Table 1. For each membrane, the active surface area was $0.038 \mathrm{~m}^{2}$ and the total active surface of each membrane type was thus $0.76 \mathrm{~m}^{2}$. The spacer thickness between two membranes was $0.5 \mathrm{~mm}$ (PC-SA membranes)

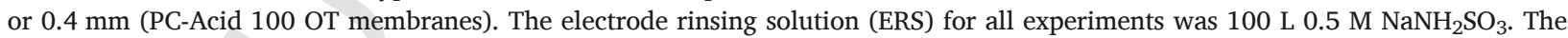
equipment was used in the feed and bleed modus and a full scheme is presented in Fig. 2, which is a modification of the scheme presented previously (Ghyselbrecht et al., 2020). The diluate was also recirculated over a $60 \mu \mathrm{m}$ cartridge filter and a UV-C lamp with an aquarium recirculation pump to minimize microbial growth (same as above). 


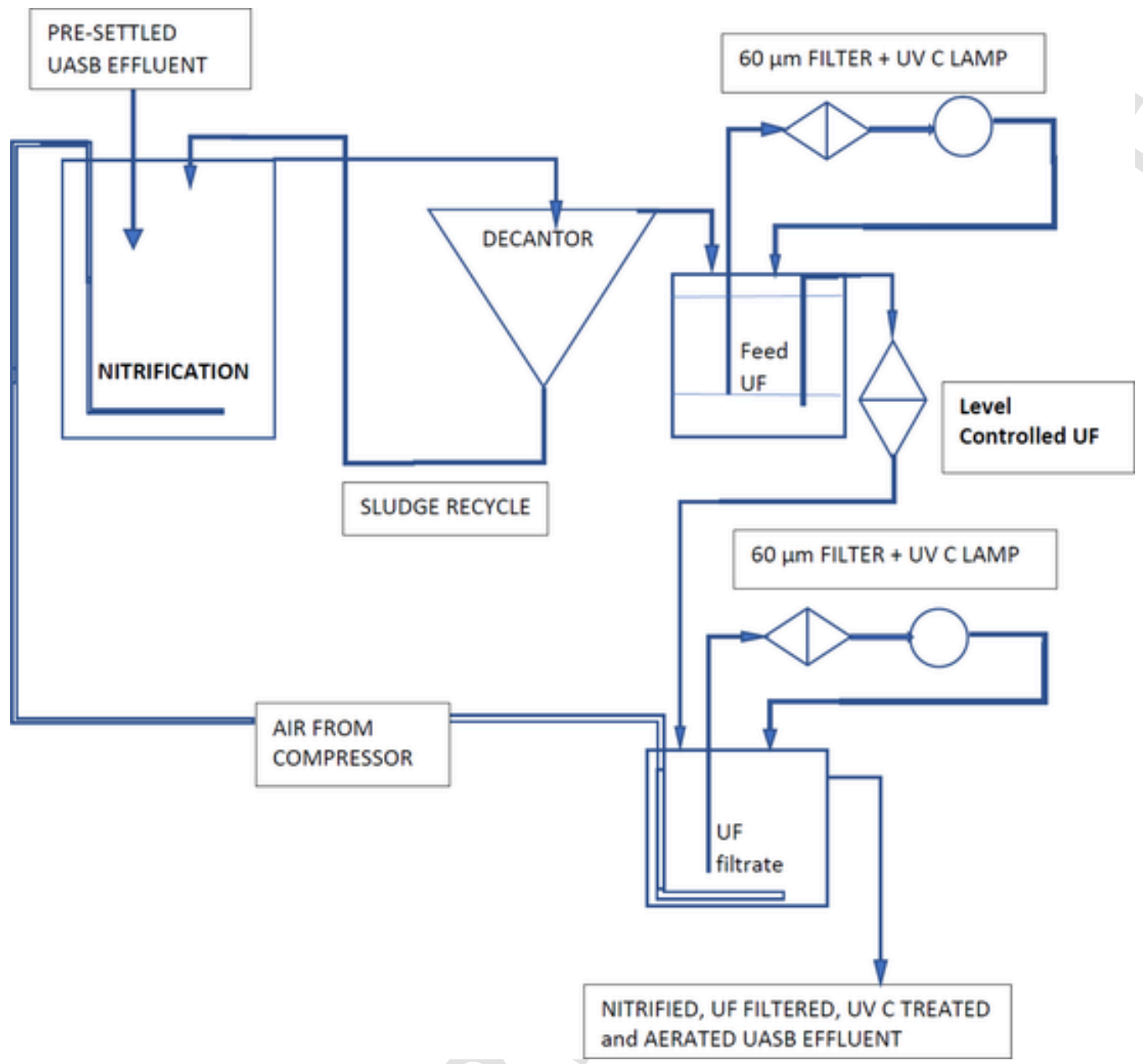

Fig. 1. Schematic diagram of the finally implemented pre-treatment steps on pilot scale to produce suitable feed water for the aSED pilot installation; adapted from Meesschaert et al. (2020), Ghyselbrecht et al. (2020). The backwash piping of the UF is omitted from the figure.

Table 1

Overview of the characteristics of the membranes.

\begin{tabular}{|c|c|c|c|c|}
\hline Type of membrane & Functional group & Thickness $\left(\mu_{\mathrm{m}}\right)$ & Perm-selectivity & Electrical resistance $\left(\Omega \mathrm{cm}^{2}\right)$ \\
\hline PC-SA & $-\mathrm{NR}_{3}^{+}$ & $180-220$ & $>0.95$ & \\
\hline PC-ACID 100 OT & Unknown & Unknown & Unknown & Unknown \\
\hline PC-MVA & $-\mathrm{NR}_{3}^{+}$ & 110 & $>0.97$ & 20 \\
\hline PC-SK & $-\mathrm{SO}_{3}^{-}$ & $160-200$ & $>0.95$ & 2.5 \\
\hline PC-SC & $-\mathrm{SO}_{3}^{-}$ & 400 & $>0.94$ & 9 \\
\hline
\end{tabular}

\subsection{Experimental procedure}

An overview of the experiments and experimental conditions is given in Table 2.

\subsubsection{Experiment 1}

In the first experiment the pilot installation was used with the PC-SA/PC-MVA/PC-SC combination of membranes. The aim of the experiment was to investigate if the results that could be obtained in short time lab scale or pilot scale experiments (3 h) can be extended to continuous long-term experiments. The lab scale experiments were either performed on synthetic wastewaters (Zhang et al., 2013, 2012) or on nitrified UASB effluent (Ghyselbrecht et al., 2020). A short time pilot scale experiment was also performed on 


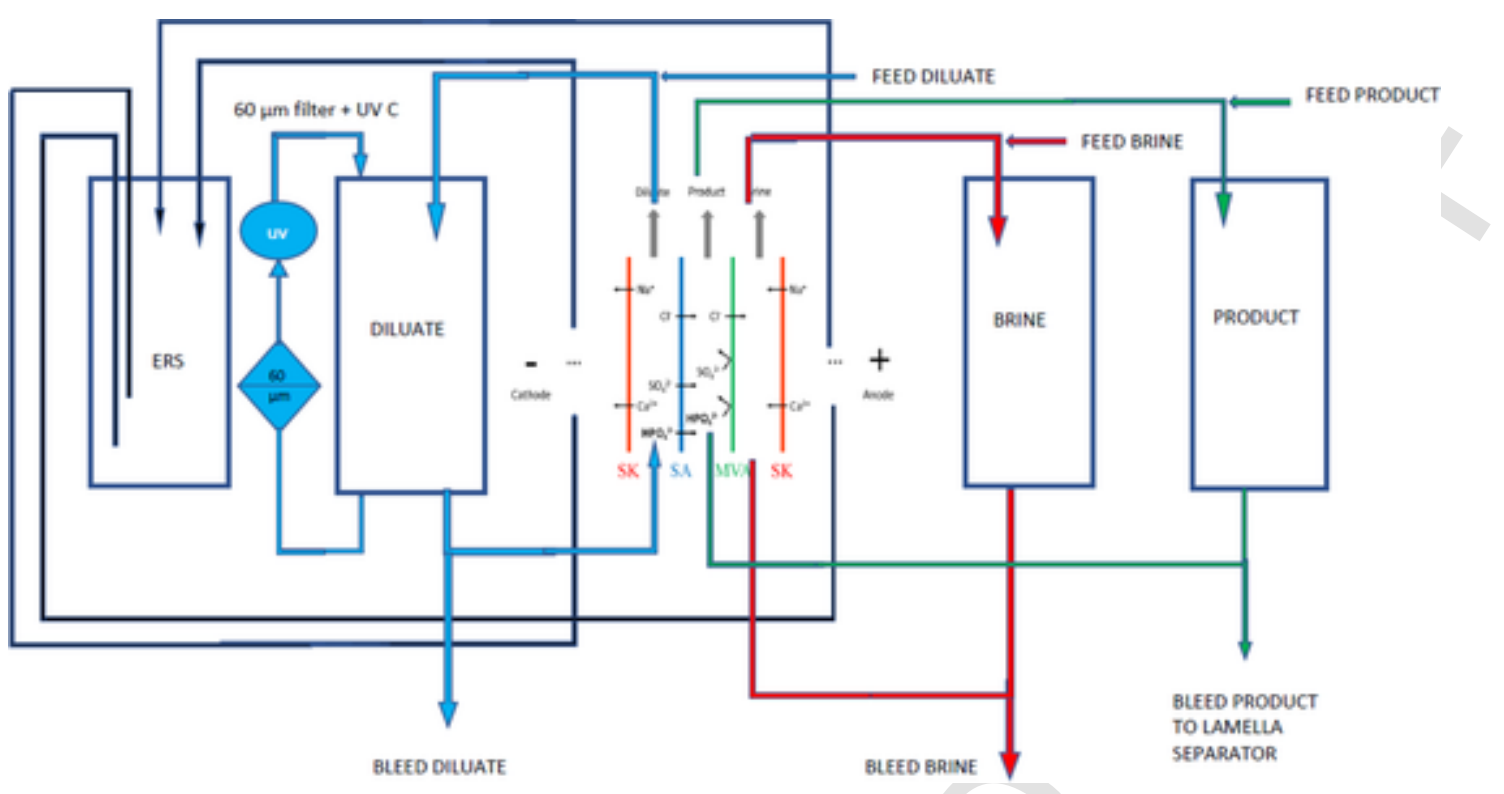

Fig. 2. Schematic diagram of the selectrodialysis process.Adapted from Ghyselbrecht et al. (2020).

nitrified UASB effluent (Ghyselbrecht et al., 2020). In practice the goal of Experiment 1 A was to (1) desalinate the pre-treated UASB effluent, (2) investigate if phosphate can migrate against a positive concentration gradient and accumulate in the product, (3) to verify if the chosen flow rates of the feed (and bleed) to diluate and brine vessel resulted in at least a double concentration of nitrate and potassium in the brine bleed relative to in the pre-treated UASB effluent.

The feed vessel contained $200 \mathrm{~L}$ pre-treated UASB effluent (nitrified, ultra-filtrated and UV C treated). The brine and product vessels contained $200 \mathrm{~L}$ of $0.075 \mathrm{M} \mathrm{NaCl}$ and $0.15 \mathrm{M} \mathrm{NaCl}$, respectively, which were prepared in process water of the company. The $\mathrm{NaCl}$ ('Rectapure' grade) was from VWR Chemicals. In Experiment $1 \mathrm{~A}$ the brine and product solutions were at the start already enriched with ions from a previous experiment. The phosphate-P concentration in the product was about $50 \mathrm{mg} \mathrm{L}^{-1}$, which is about the same as in the pre-treated effluent $\left(42-56 \mathrm{mg} \mathrm{L}^{-1}\right)$.

The continuous experiment on pilot scale was realized in the feed and bleed modus of the equipment. In Experiment $1 \mathrm{~A}$, the diluate and brine were discharged in an intermittent way, resulting in a net flow rate of $20 \mathrm{~L} \mathrm{~h}^{-1}$ (Diluate-effluent) and $5 \mathrm{~L} \mathrm{~h}{ }^{-1}$ (Brine-effluent), respectively. The discharges of the vessels were compensated by feeding $20 \mathrm{~L} \mathrm{~h}^{-1}$ fresh pre-treated effluent to the diluate vessel and $5 \mathrm{~L} \mathrm{~h}^{-1}$ process water to the brine vessel. The ratio of these net flow rates was thus 4 and this was chosen in the objective that at least half of the compound of interest must be recovered and that the recovered product must be present in the brine at a concentration of at least the double of in the feed. The product stream was used in batch.

After Experiment $1 \mathrm{~A}$ an intensive CIP was necessary to restore a flow rate of more than $400 \mathrm{~L} \mathrm{~h}^{-1}$ over the diluate compartments of the stack. The procedure contained the following rinsing steps using each time $30 \mathrm{~L}: 0.15 \mathrm{M} \mathrm{NaCl}$ (35'), $0.5 \mathrm{M} \mathrm{HCl}$ (45'), RO water (10'; 2x), 1\% NaOH (18 h), RO water (10'; 2x), $0.5 \mathrm{M} \mathrm{NH}_{3} \mathrm{SO}_{3}$ (2 h), RO water (10', 2x), 1\% NaOH (18 h), RO water (10', 2x), $0.5 \mathrm{M}$ $\mathrm{NH}_{3} \mathrm{SO}_{3}(2 \mathrm{~h})$ and $\mathrm{RO}$ water $(10$ ', $2 \mathrm{x})$. The rinsing steps with amidosulphonic acid $\left(\mathrm{NH}_{3} \mathrm{SO}_{3}\right)$ were the most effective.

Table 2

Summary of the experimental conditions of the various pilot scale experiments. Electrode rinsing solution (ERS) for all experiments: $0.5 \mathrm{M} \mathrm{NaNH}_{2} \mathrm{SO}_{3}$. A constant voltage of $25 \mathrm{~V}$ was applied for all experiments. All membranes were from PCA, Germany (PC-membranes). SA: standard anion-exchange membrane; MVA: monovalent selective anion-exchange membrane, SC: standard cation-exchange membrane and Acid 100 OT: anion-exchange membrane normally used for sulphuric acid production.

\begin{tabular}{|c|c|c|c|c|c|}
\hline $\begin{array}{l}\text { Exp. } \\
\text { No. }\end{array}$ & $\begin{array}{l}\text { Operating } \\
\text { mode }\end{array}$ & $\begin{array}{l}\text { Diluate } \\
\text { Nitrified effluent }\end{array}$ & $\begin{array}{l}\text { Brine } \\
\text { initial } \\
0.075 \mathrm{M} \mathrm{NaCl}\end{array}$ & $\begin{array}{l}\text { Product } \\
\text { initial } \\
0.15 \mathrm{M} \mathrm{NaCl}\end{array}$ & $\begin{array}{l}\text { Membrane } \\
\text { combination } \\
\text { (20 cell triplets) }\end{array}$ \\
\hline 1 & $\begin{array}{l}\text { A:feed \& bleed } \\
\text { in diluate \& brine } \\
\text { B: full feed and bleed. }\end{array}$ & $200 \mathrm{~L}$ & $200 \mathrm{~L}$ & $200 \mathrm{~L}$ & $\begin{array}{l}\text { SA/ } \\
\text { MVA/SC }\end{array}$ \\
\hline 2 & $\begin{array}{l}\text { (Batch) } \\
\text { Full feed \& bleed }\end{array}$ & $200 \mathrm{~L}$ & $200 \mathrm{~L}$ & $50 / 200 \mathrm{~L}$ & $\begin{array}{l}\text { Acid } 100 \text { OT/ } \\
\text { MVA/SC }\end{array}$ \\
\hline 3 & $\begin{array}{l}\text { (Batch) } \\
\text { Full feed \& bleed }\end{array}$ & $\begin{array}{l}200 \mathrm{~L} \\
\text { A: aerated with } \\
\text { pond aerator } \\
\text { B and C: aerated with } \\
\text { compressed air }\end{array}$ & $200 \mathrm{~L}$ & $50 / 200 \mathrm{~L}$ & $\begin{array}{l}\text { Acid } 100 \text { OT/ } \\
\text { MVA/SC }\end{array}$ \\
\hline
\end{tabular}


In Experiment 1B the product was also discharged at flow rate of $5 \mathrm{~L} \mathrm{~h}^{-1}$ (Product-effluent). In addition to the aims concerning the feed and the brine of Experiment $1 \mathrm{~A}$, the aim now was also to produce a product stream with a doubled concentration of phosphate. The discharge of the diluate vessel was compensated with pre-treated effluent. $0.075 \mathrm{M} \mathrm{NaCl}$ and $0.15 \mathrm{M}$ NaCl solution (both prepared in process water) were fed to the brine vessel respectively the product vessel. The liquid present in the diluate vessel of the aSED equipment was also continuously recycled over a $60 \mu \mathrm{m}$ filter and an UV-C lamp (Clean Pond UV-C 11 Watt) to prevent biofilm formation as explained; see Fig. 2. A constant voltage of $25 \mathrm{~V}$ was applied.

During the Experiments $1 \mathrm{~A}$ and $1 \mathrm{~B}$ the diluate, brine, product and ERS were recirculated over an internal $25 \mu \mathrm{m}$ filter and the stack with a flow rate of 400, 400, 400 and $600 \mathrm{~L} \mathrm{~h}^{-1}$, respectively. The chosen flow rates are in line with the guidelines of the stack manufacturer, in this way assuring optimal hydrodynamic conditions inside the stack.

\subsubsection{Experiment 2}

In the second experiment the PC-Acid 100 OT/PC-MVA/PC-SC membrane combination was used to treat pre-treated UASB effluent. The aim of the experiment was to investigate if the results that were obtained in short time batch experiments ( $3 \mathrm{~h})$ with this membrane combination (Ghyselbrecht et al., 2020), can be confirmed during a long-term continuous experiment. The diluate, brine and product vessel were initially filled with $200 \mathrm{~L}$ of the pre-treated UASB effluent, $200 \mathrm{~L} 0.075 \mathrm{M} \mathrm{NaCl}$ and $50 \mathrm{~L} 0.15 \mathrm{M}$ NaCl, respectively which were now prepared with pure RO-water and the $\mathrm{NaCl}$ used was 'pro analyse' from Across. During the first $2 \mathrm{~h}$, the aSED pilot was operated in batch mode to reduce the initial salt concentration in the diluate before switching to the feed and bleed mode. During this initial batch mode and during the following feed and bleed mode the same flow rates through the stack were used as is Exp. 1. A constant voltage of $25 \mathrm{~V}$ was applied and the diluate was recycled over the UV lamp. After $2 \mathrm{~h}$ and after adding an extra volume of $150 \mathrm{~L}$ of $0.15 \mathrm{M} \mathrm{NaCl}$ to the product vessel, the feed and bleed mode was applied at diluate, brine and product side. The bleed of the product (Product-effluent; $5 \mathrm{~L} \mathrm{~h}^{-1}$ ) was fed to a lamella separator. $\mathrm{CaCl}_{2} \cdot 2 \mathrm{H}_{2} \mathrm{O}\left(4770 \mathrm{mg} \mathrm{L} \mathrm{Ca}^{2}\right.$; diluted from a technical calcium chloride solution from Nedmag Industries (Veendam, The Netherlands) was dosed to this so that the phosphate present could precipitate as $\mathrm{Ca}_{3}\left(\mathrm{PO}_{4}\right)_{2}$.

To restore the hydrodynamic properties of the stack after Experiment 2 a CIP was necessary. After rinsing with RO-water (20') the diluate and product compartments and the concentrate compartments of the stack were rinsed with respectively 30 litres of 0.5 $\mathrm{NH}_{3} \mathrm{SO}_{3}$ and $0.5 \mathrm{M} \mathrm{HNO}_{3}$ for $18 \mathrm{~h}$. After three successive rinsing steps with RO water (10') the maximum attainable flow rate of the three different compartments largely exceeded $400 \mathrm{~L} \mathrm{~h}^{-1}$.

\subsubsection{Experiment 3}

A third experiment on nitrified UASB effluent, also with the PC-Acid 100 OT/PC-MVA/PC-SC membrane combination was set up to investigate if it was possible to enlarge the process time by introducing intermittent CIP. The experiment lasted for 21 days and was divided in three phases of 7 days that were separated by a preventive CIP procedure of the diluate circuit. This CIP procedure consisted of 2 rinsing steps of $1 \mathrm{~h}$ each: $12 \% \mathrm{HNO}_{3}$ followed by $1 \% \mathrm{NaOH}$; in between, the diluate circuit was rinsed three times with $\mathrm{RO}$ water. The actual process conditions and solutions used were as above and started with two hours in the batch mode. To disturb the process as less as possible, after each CIP procedure the previously harvested diluate was reintroduced into the diluate vessel. The bleed of the product was treated in the lamella separator as above. It was further the aim to investigate if (partial) removal of DIC by aeration would affect transport of other ions during aSED and further would be beneficial for the purity of the recovered calcium phosphate from the lamella separator as judged by the $\mathrm{Ca} / \mathrm{P}$ ratio of the precipitate. In the first week (Exp. $3 \mathrm{~A}$ ) the feed was aerated with a pond aerator (Silenta 3600; Velda). In weeks 2 and 3 (Exp. 3B and C) the feed was aerated with compressed air in such a way that there was just no spill over when the IBC was full $(850 \mathrm{~L})$; see Fig. 1.

\subsection{The lamella separator}

The lamella separator was built according to Alvaro et al. (1993). The bleed of the product of the SED was fed to the first compartment and the calcium chloride solution was fed to the compartment before the settling tank which was also mixed with a mechanical stirrer; see also Fig. 6 in the results section. The volume of this last compartment and of the settling chamber were respectively 5.8 and 25 litres.

\subsection{Analytical methods}

During the batch phases of the experiments samples of the circulating fluids were collected at the start of each experiment and then every $30 \mathrm{~min}$. During the continuous long-term pilot experiment (in feed and bleed mode) samples were taken once a day. The following parameters were analysed: $\mathrm{pH}$, conductivity, chloride, nitrate, phosphate, sulphate, sodium, ammonium, potassium, calcium, magnesium, DIC and TOC concentration. Details of the methods used have been published elsewhere (Meesschaert et al., 2020). X-ray diffraction patterns were recorded using a Malvern PANalytical Empyrean powder diffractometer using CuK $\alpha$ radiation and a PIXcel3D detector.

\subsection{Data analysis}

The current efficiency of an ion A is defined as the ratio of the electrical current used for the transport of ion A to the total electrical current (Ghyselbrecht et al., 2012). The current efficiency of ion A is calculated by: 


$$
\eta_{A}=\frac{\left(\Delta m_{A}(t) / M_{A}\right) z F}{n I(\Delta t)} \times 100(\%)
$$

where $\Delta \mathrm{mA}(\mathrm{t})$ is the weight of the transferred ion A during the considered time period $(\mathrm{g}), M_{\mathrm{A}}$ is the molar mass of ion A $\left(\mathrm{g}\right.$ mol $\left.{ }^{-1}\right)$, $\mathrm{z}$ is the valence of ion A (-), F is the Faraday constant (96485 C mol${ }^{-1}$ ), $\Delta \mathrm{t}$ is the time period (s), I is the mean current for that time period (A) and $\mathrm{n}$ is the number of cell triplets (-) in the aSED stack, which 20 . In this study, the current efficiency was calculated for the different ions present at diluate side of the anion-exchange membranes, thus for either the PC-SA or the PC-Acid 100 OT membranes.

\section{Results}

\subsection{Characterization of the feed water}

Table 3 gives an overview of the characteristics of the feed water of the potato processor while going through the pre-treatment steps.

After nitrification of the UASB effluent, the concentration of ammonium dropped to zero and an equivalent molar amount of nitrate was formed. The nitrification consumes a bi-equimolar amount of DIC. It is calculated, for a $\mathrm{NH}_{4}^{+}-\mathrm{N}$ concentration of $362 \pm 35$ mg L $\mathrm{L}^{-1}$ $26 \pm 2 \mathrm{mmol} \mathrm{L}^{-1}$; Table 3) that the DIC should decrease by (12 mg.mmol ${ }^{-1}$ × $\left.2 \times 26 \pm 2 \mathrm{mmol} \mathrm{L}^{-1}\right)=624 \pm 24 \mathrm{mg} \mathrm{L}^{-1}$. Table 3 shows that the initial DIC of $731 \pm 156 \mathrm{mg} \mathrm{L}^{-1}$ in the UASB effluent decreases to $96 \pm 32 \mathrm{mg} \mathrm{L}^{-1}$, which is a decrease of $635 \pm 188$ $\mathrm{mg} \mathrm{L}^{-1}$. This is in excellent agreement with the calculated value. The ultra-filtration resulted in a further reduction of the TOC from $36 \pm 13$ to $23 \pm 4 \mathrm{mg} \mathrm{L}^{-1} \mathrm{C}$. Apart from the TOC concentration, the composition of this UF filtrate was completely analogous to the nitrified effluent. This UF filtrate acted as the initial diluate in the different experiments. In Experiment 3, the IBC with the UF filtrate was aerated to reduce further the residual DIC content; Table 3 shows that it dropped from $92 \pm 12$ to $51 \pm 9 \mathrm{mg} \mathrm{L}^{-1} \mathrm{C}$ in Experiment 3 A.

\subsection{Feed and bleed experiments}

\subsubsection{Exp. 1: stack with PC-SA membranes}

In Experiment 1 the same membrane combination was used as described earlier for batch tests on synthetic wastewaters on lab scale (Zhang et al., 2013, 2012) and on nitrified UASB effluent on lab scale and pilot scale (Ghyselbrecht et al., 2020). In Experiment $1 A$ the initial phosphate-P concentration of the feed and the product stream were about the same and the brine contained various concentrations of ions originating from the previous experiment at the Agristo site. The most important data are given in Fig. 3. At a voltage of $25 \mathrm{~V}$ a constant current was obtained of 0.9-1.0 A during a time course of 14 days. The conductivity of the feed was about $5 \mathrm{mS} \mathrm{cm}^{-1}$ and decreased to $1.5 \mathrm{mS} \mathrm{cm}^{-1}$ in the circulating diluate; the desalination was thus $70 \%$. The pH of the diluate and brine were about 7.5-8.0, but the $\mathrm{pH}$ of the product stabilized at 9.8 .

The phosphate concentration in the product stream increased to $280 \mathrm{mg} \mathrm{L}^{-1}$, which is 4.66 times the concentration in the feed to the aSED; no phosphate migrated further from the product to the brine; Fig. 3A. The current efficiency of phosphate transport through the PC-SA membrane was 1,7\%. The PC-MVA membrane completely blocked phosphate transport. The current efficiency of the PC-SA membrane for DIC was $9.15 \%$ and the final concentration of DIC in the product increased to $790 \mathrm{mg} \mathrm{C.L}{ }^{-1}$; Fig. 3B.

Fig. $3 \mathrm{C}$ shows that sulphate also accumulates in the product, while it simultaneously is washed out from the brine by its feed (process water) and bleed, the latter indicating that also sulphate did not permeate the PC-MVA membrane.

Table 3

Characteristics of the feed water of the aSED pilot installation while going through the pretreatment steps. "Aerated UF-filtrate" is obtained by blowing air through the IBC with UF-filtrate (Exp. 3A).

\begin{tabular}{|c|c|c|c|c|}
\hline & UASB effluent & Nitrified effluent & UF filtrate ${ }^{*}$ & $\begin{array}{l}\text { Aerated } \\
\text { UF filtrate }\end{array}$ \\
\hline $\mathrm{pH}[-]$ & $7.5 \pm 0.2$ & $7.4 \pm 0.3$ & $7.5 \pm 0.2$ & $7.8 \pm 0.3$ \\
\hline Conductivity $\left[\mathrm{mS} \mathrm{cm}^{-1}\right]$ & $5.1 \pm 0.1$ & $5.0 \pm 0.2$ & $5.1 \pm 0.1$ & $5.4 \pm 0.1$ \\
\hline $\mathrm{Cl}-\left[\mathrm{mg} \mathrm{L}^{-1}\right]$ & $333 \pm 19$ & $330 \pm 21$ & $336 \pm 20$ & $344 \pm 23$ \\
\hline $\mathrm{NO}_{3}^{-}-\mathrm{N}\left[\mathrm{mg} \mathrm{L}^{-1}\right]$ & $0 \pm 0$ & $358 \pm 23$ & $351 \pm 17$ & $360 \pm 28$ \\
\hline $\mathrm{PO}_{4}^{3-}-\mathrm{P}\left[\mathrm{mg} \mathrm{L}^{-1}\right]$ & $55 \pm 9$ & $54 \pm 7$ & $56 \pm 8$ & $59 \pm 10$ \\
\hline $\mathrm{SO}_{4}^{2-}\left[\mathrm{mg} \mathrm{L}^{-1}\right]$ & $49 \pm 8$ & $50 \pm 9$ & $48 \pm 10$ & $51 \pm 11$ \\
\hline $\mathrm{Na}+\left[\mathrm{mg} \mathrm{L}^{-1}\right]$ & $90 \pm 9$ & $88 \pm 12$ & $86 \pm 10$ & $85 \pm 11$ \\
\hline $\mathrm{NH}_{4}^{+}-\mathrm{N}\left[\mathrm{mg} \mathrm{L}^{-1}\right]$ & $362 \pm 35$ & $0 \pm 0$ & $0 \pm 0$ & $0 \pm 0$ \\
\hline $\mathrm{K}+\left[\mathrm{mg} \mathrm{L}^{-1}\right]$ & $1564 \pm 112$ & $1547 \pm 87$ & $1542 \pm 68$ & $1568 \pm 64$ \\
\hline $\mathrm{Ca}^{2 ?}\left[\mathrm{mg} \mathrm{L}^{-1}\right]$ & $60 \pm 19$ & $58 \pm 11$ & $55 \pm 13$ & $56 \pm 12$ \\
\hline $\mathrm{Mg}_{2+}\left[\mathrm{mg} \mathrm{L}^{-1}\right]$ & $60 \pm 13$ & $58 \pm 9$ & $62 \pm 6$ & $63 \pm 4$ \\
\hline $\mathrm{DIC}\left[\mathrm{mg} \mathrm{L}^{-1} \mathrm{C}\right]$ & $731 \pm 156$ & $96 \pm 32$ & $92 \pm 12$ & $51 \pm 9$ \\
\hline TOC $\left[\mathrm{mg} \mathrm{L}^{-1} \mathrm{C}\right]$ & $222 \pm 88$ & $36 \pm 13$ & $23 \pm 4$ & $24 \pm 6$ \\
\hline
\end{tabular}

* Acted as the initial diluate for the Experiments 1 and 2.

** Acted as the feed water for the diluate circuit in Experiment 3A. 
The current efficiency of chloride ions through the PC-SA membrane is about $18 \%$ and constant during the whole experiment; Fig. 3D. Notwithstanding this the concentration of chloride in the product is decreasing globally from 3750 to about 300 mg $\mathrm{L}^{-1}$, but in the beginning of the experiment the decrease is faster than at the end; Fig. 3D. Nitrate passes the PC-SA membrane very easily; the current efficiency for nitrate transport is about $42 \%$. The steady state concentrations of chloride and nitrate at the end of the experiment in the brine vessel which is replenished with process water are about 875 and about $1000 \mathrm{mg} \mathrm{L}^{-1}$ respectively; Figs. 3D and 3E.

Calcium ions are moving from the feed to the brine, while the concentration in the product remains constant; Fig. 3F. The same can be said for the magnesium ions; Fig. 3G.

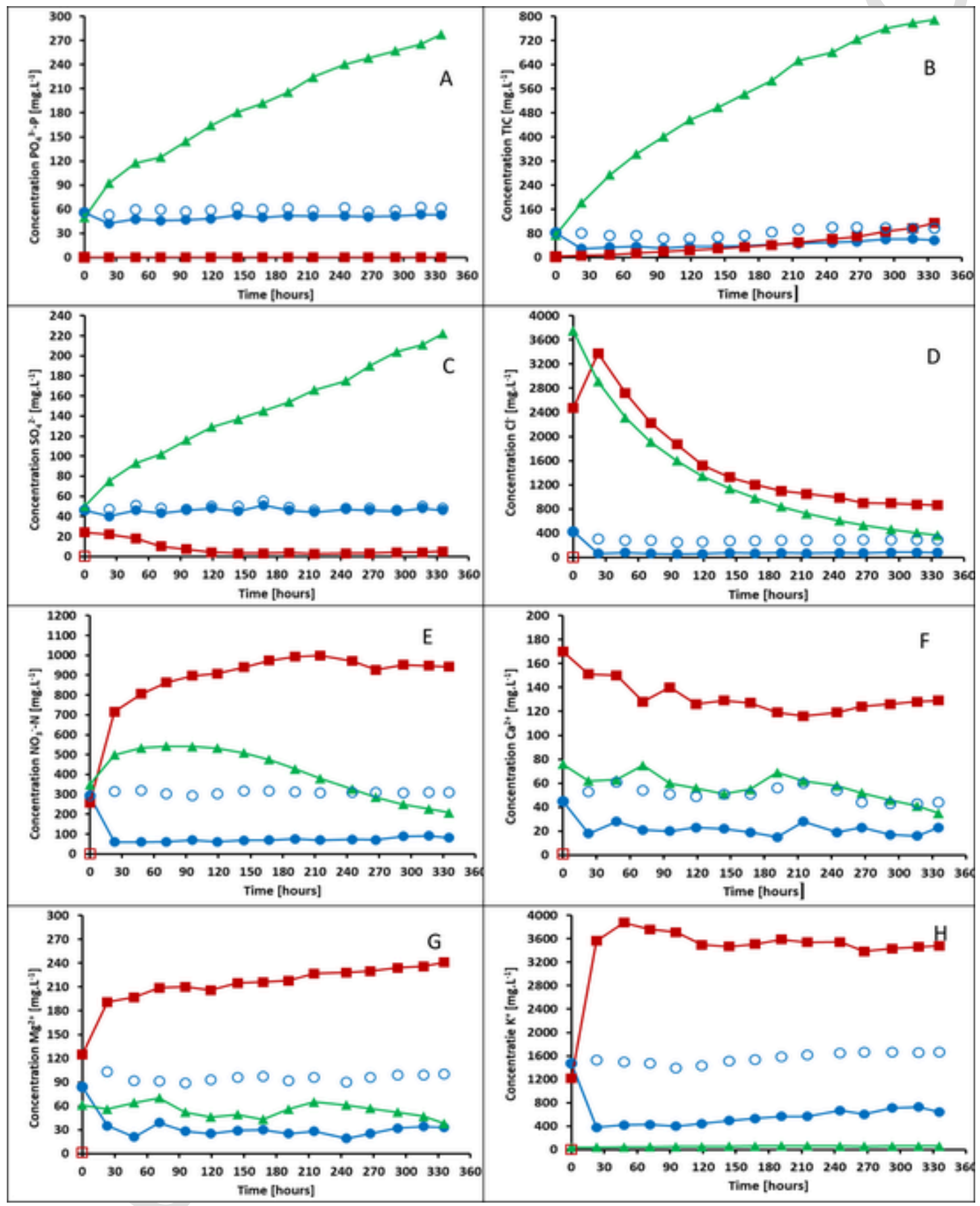

Fig. 3. Results obtained during feed and bleed Experiment 1 A using PC-SA/PC-MVA/PC-SC membranes; the product being operated in batch mode. As function of the time course of the experiment the concentration of the different ions is given for phosphate (Fig. 3A), DIC (Fig. 3B), sulphate (Fig. 3C), chloride (Fig. 3D), nitrate-N (Fig. 3E), calcium (Fig. 3F), magnesium (Fig. 3G) and potassium (Fig. 3H). Feed: open symbols; circulating fluids: closed symbols; diluate, product and brine are respectively given in blue (circles), green (triangles) and red (squares). 
The initial concentrations of potassium and nitrate- $\mathrm{N}$ are 1500 and $310 \mathrm{mg} \mathrm{L}^{-1}$ respectively, they decrease in the diluate to about 500 and $70 \mathrm{mg} \mathrm{L}^{-1}$ respectively and they accumulate in the brine to a steady state concentration of 3500 and $950 \mathrm{mg} \mathrm{L} \mathrm{L}^{-1}$ respectively. In contrast to potassium where the steady state concentration in the brine is already reached after one day (Fig. $3 \mathrm{H}$ ), with nitrate this steady state concentration is only reached at the end of the experiment (Fig. 3E).

In Experiment $1 B$ the aim is to perform long-term experiments on pilot scale in full feed and bleed mode: also the liquid in the product vessel changed with $0.15 \mathrm{M} \mathrm{NaCl}$ at $5 \mathrm{~L} \mathrm{~h}^{-1}$. The results obtained are summarized in Fig. 4 . The experiment lasted for 16 days, after which time the flow rate through the diluate compartments of the stack became too low because of scaling and or fouling of the system making CIP cleaning necessary. Throughout the first 14 days a stable working system was obtained. During that period, no significant changes in the $\mathrm{pH}$ of the circulating fluids in the diluate, product or brine compartments of the system were noticed.

After $30 \mathrm{~h}$ a stable situation is reached in which the system is operating at a current of 1 A under 25 Volt electric charge; Fig. 4A. The rapid decline of the conductivity of the diluate at the start of experiment (Fig. 4B) reflects its increasing desalination. In this initial period the conductivity of the diluate decreases from about 5 to $1.5 \mathrm{mS} / \mathrm{cm}$ as in Experiment $1 \mathrm{~A}$; the conductivity of the product declines a bit, while the conductivity of the brine increases from 7.5 to an average value of $14 \mathrm{mS} / \mathrm{cm}$. (Fig. 4B).

The nitrate concentration decreases from $200-280 \mathrm{mg} \mathrm{L}^{-1}$ nitrate- $\mathrm{N}$ in the feed to about $50 \mathrm{mg} \mathrm{L}^{-1}$ nitrate-N in the diluate (Fig. 4C). After the initial period, the nitrate- $\mathrm{N}$ concentration in the product increased slowly from 250 till 350 ppm, following the increasing nitrate- $\mathrm{N}$ concentration of the feed. In the bleed of the brine $\left(5 \mathrm{~L} \mathrm{~h}^{-1}\right)$ the nitrate- $\mathrm{N}$ concentration is also $400-560 \mathrm{mg} \mathrm{L}-1$ nitrate- $\mathrm{N}$ and thus almost double as in the diluate feed. As the ratio of the net flow rates of diluate and product is 4 , and the ratio of the concentrations of nitrate- $\mathrm{N}$ in the product stream over the value in the feed stream is $2,50 \%$ of the nitrate- $\mathrm{N}$ was extracted from the feed to the brine.

The chloride concentration of the circulating diluate (about 50-70 $\mathrm{mg} \mathrm{L}^{-1}$; Fig. 4D) indicates that most of the chloride in the feed (330 $\mathrm{mg} \mathrm{L}^{-1}$; Table 3) migrated towards the anode and accumulated in the brine. The concentration of chloride in the feed of the product varies from 4200 to $4700 \mathrm{mg} \mathrm{L}^{-1}$ and decreases in the product to $2500-3500 \mathrm{mg} \mathrm{L}^{-1}$. Initially the chloride concentration in the brine increased, later it stabilized at the initial concentration. At around $200 \mathrm{~h}$, in one hour about 29 gram chloride enters the system via the feed of the diluate $(6.5$ gram $)$ and via the feed of the product $(22.5 \mathrm{~g})$; about 1.5 gram leaves the system via the bleed of the diluate, and 15 gram and 12.5 gram are respectively removed via the brine and product bleeds.

The sodium concentration in the feed (Table 3; Fig. 4E) is rather low (80-90 $\mathrm{mg} \mathrm{L}^{-1}$ ) and does not vary during the process. About $50 \%$ of it migrates to the brine. The sodium concentration in the product does not change.

The feed (to the diluate) is the only source of potassium: at the stable phase of the experiment and at a concentration of 1200 $\mathrm{mg} \mathrm{L}^{-1}$ this is 24 gram in an hour. The concentration in the bleed of the diluate is about $400 \mathrm{mg} \mathrm{L}^{-1}$ and thus 16 grams migrates to the brine in one hour, which is also the amount of potassium that is leaving the system in one hour. In this way $66 \%$ of the potassium is recovered. Since the actual bleed is only $5 \mathrm{~L} \mathrm{~h}^{-1}$, at steady state, the potassium concentration in the brine and its bleed should be around $3.2 \mathrm{~g} \mathrm{~L}^{-1}$, which agrees with what can be seen in Fig. 4F.

The concentration of calcium (Fig. 4G) and magnesium (Fig. 4H) in the nitrified UASB effluent varied a bit, which is probably depending on the type of process water that is used at a certain moment and its hardness, but for both bivalent cations the concentration is about $50 \mathrm{mg} \mathrm{L}^{-1}$. In the circulating diluate and the corresponding bleed the concentration of both ions dropped to about $15 \mathrm{mg} \mathrm{L}^{-1}$. Migration of these ions to the brine is taking place, as evidenced by the concentrations in the brine. So, in one hour, 700 mg enters the brine and, in steady state, also leaves the brine vessel via its bleed. Since the bleed of the brine is $5 \mathrm{~L}$, the expected concentration of calcium and magnesium in the brine is $140 \mathrm{mg} \mathrm{L}^{-1}$. This adds to the $45 \mathrm{mg} \mathrm{L}^{-1}$ which is present in the initial fluid and the feed of the brine stream. Fig. 4G shows indeed a concentration of $180-185 \mathrm{mg} \mathrm{L}^{-1}$ for calcium in the brine. Fig. $4 \mathrm{H}$ shows that the steady state concentration for magnesium is attained somewhat slower but finally reached the expected value.

Fig. 4I shows that the concentration of phosphate in the feed to the diluate varied considerably from 32 to $52 \mathrm{mg} \mathrm{L}^{-1} \mathrm{phosphate-P}$ (which is between 100 and $150 \mathrm{mg} \mathrm{L}^{-1}$ phosphate). When compared to what happens with other ions, the migration of phosphate to the product stream is rather low. The interpretation is hampered by the variation in the phosphate concentration of the feed: in the circulating diluate and thus in its bleed the concentration of phosphate-P dropped only 5 (1 to 10) $\mathrm{mg} \mathrm{L}^{-1}$. Initially the concentration in the product increases from 0 to about $50 \mathrm{mg} \mathrm{L}^{-1}$, but then decreased. The current efficiency of phosphate was, just as in Exp. $1 \mathrm{~A}$, maximally $1.7 \%$ (at time $=83 \mathrm{~h}$ ). This may indicate that the intensive CIP did not alter the properties of the membranes. Between 80 and $160 \mathrm{~h}$ the average phosphate-P concentration in the feed was $45 \mathrm{mg} \mathrm{L}^{-1}$. The concentration in the product reached an average value of $40 \mathrm{mg} \mathrm{L}^{-1}$. Thus, in one hour $900 \mathrm{mg}$ phosphate-P was added to the system and $200 \mathrm{mg}$ were recovered in the product; corresponding with a yield of about $22 \%$.

The concentration of sulphate in the nitrified UASB effluent is $30-50 \mathrm{mg} \mathrm{L}^{-1}$ and about $10 \mathrm{mg} \mathrm{L}^{-1}$ is removed from it; Fig. $4 \mathrm{~J}$. The process water used to prepare the initial solutions for the brine and the product vessels as well as the feeds to these vessels contained various amounts of sulphate: $34-55 \mathrm{mg} \mathrm{L}^{-1}$.

Once stabilized, the DIC concentration of the feed to the diluate vessel is $100 \pm 25 \mathrm{mg} \mathrm{L}^{-1}$ (Fig. 4K). As mentioned, the nitrification of the UASB effluent thus does not result in the total removal of DIC. Under stable working conditions the DIC concentration

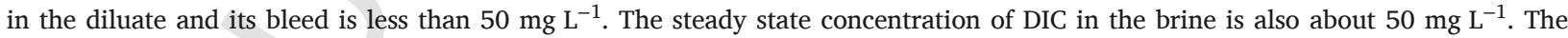
concentration of DIC in the product reaches a value of $380 \mathrm{mg} \mathrm{L}^{-1}$ after $2 \mathrm{~h}$, but then declines. At the quasi-steady state between 120 and $220 \mathrm{~h}$ five times more DIC left the system via the bleed of the product ( $5 \mathrm{~L}$ with about $225 \mathrm{mg} \mathrm{C}$. $\mathrm{L}^{-1}$ ) than via the bleed of the brine ( $5 \mathrm{~L}$ with about $50 \mathrm{mg} \mathrm{L}^{-1}$ ).

Fig. $4 \mathrm{~L}$ gives the results for the behaviour of the TOC during the experiment. With about $17 \mathrm{mg} \mathrm{L}^{-1}$, the TOC concentration in the feed during the stable phase of operation is somewhat lower than indicated in Table 3 . From the $360 \mathrm{mg}$ that enters the system in 


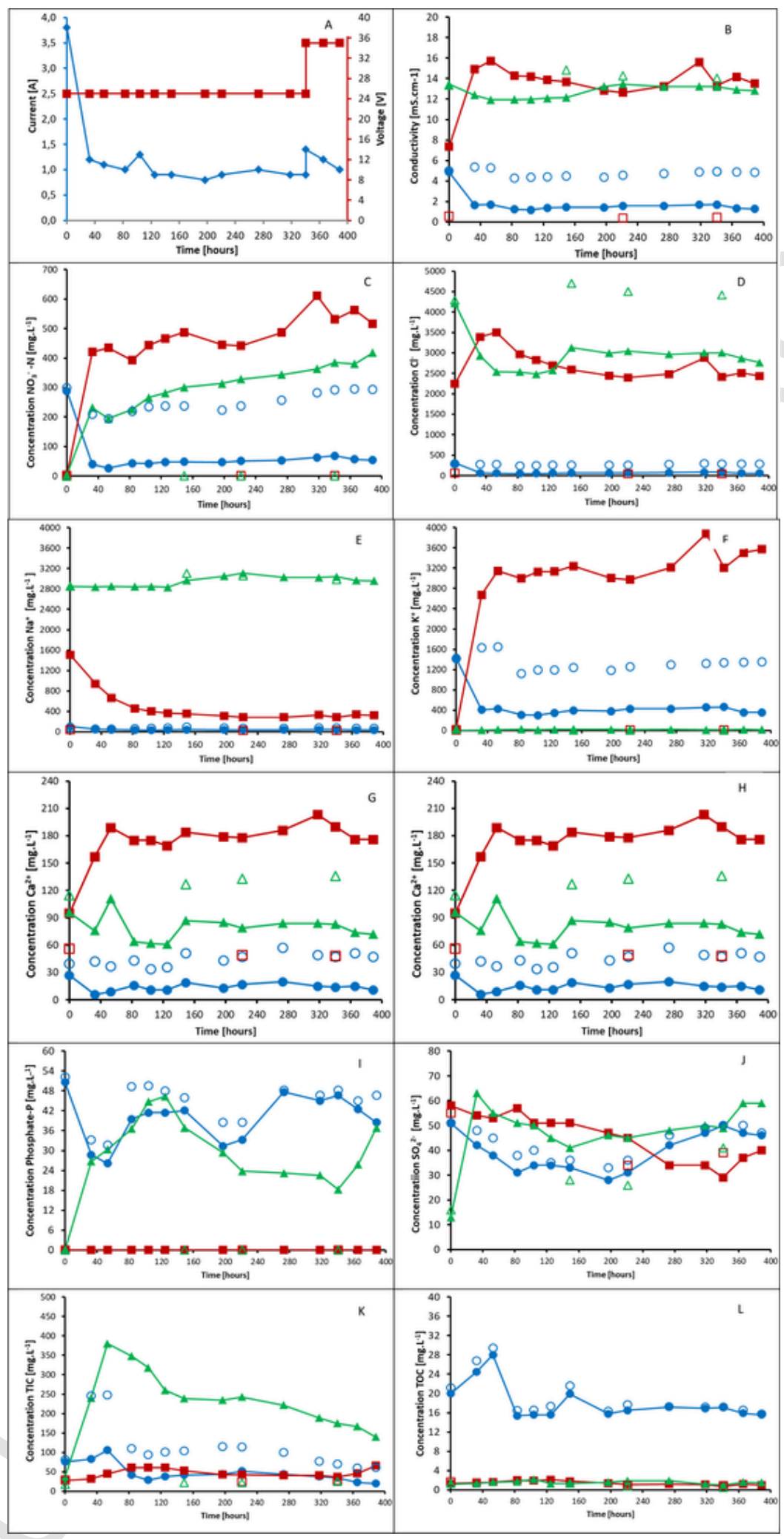

Fig. 4. Results obtained during the (full) feed and bleed Experiment 1B using PC-SA/PC-MVA/PC-SC membranes. As function of the time course of the experiment: Fig. 4A gives the voltage (red - squares) over the stack and the current (blue — diamonds) through the stack. For the different fluids, Fig. 4B gives the conductivity 
and the concentration of the different ions is given Fig. 4C (nitrate-N), 4D (chloride), 4E (sodium), 4F (potassium), 4G (calcium), 4H (magnesium), 4I (phosphate) and 4J (sulphate). Fig. 4K and Fig. 4L give respectively the course of dissolved inorganic carbon (DIC) and total organic carbon (TOC. Symbols as in Fig. 3.

one hour, $310 \mathrm{mg}$ leaves the system via the bleed of the diluate. The remaining $50 \mathrm{mg}$ TOC are exported equally divided over the bleeds of the brine and the product.

\subsubsection{Exp. 2: stack with PC-Acid 100 OT membranes}

This experiment lasted for 15 days after which a CIP cleaning was necessary and was largely comparable with Exp. 1B, except that the PC-Acid 100 OT membrane was used as anion-exchange membrane. The experiment was somewhat hampered by two pump failures in the weekend but fulfilled otherwise the expectations. The most important results are given and are summarized in Fig. 5 . In the first two hours the equipment was run in the batch mode, whereby the installation behaved exactly as in the batch test with PC-Acid 100 OT membrane as described earlier (Ghyselbrecht et al., 2020), proving the repeatability of the system. In the phases of stable working a current of $1.1 \mathrm{~A}$ was established and the conductivity of the feed decreases from 5 to $1.5 \mathrm{mS} / \mathrm{cm}$, a decrease of $70 \%$ (Fig. 5A), which is similar to what happened during the Exp. 1B (Fig. 4B). The pH of the product increases from 7.5 to 11.6 (Fig. 5B) which is different from the previous experiment where $\mathrm{pH}$ values as mentioned earlier hardly changed.

The nitrate- $\mathrm{N}$ concentration in the feed was $\pm 350 \mathrm{mg} \mathrm{L}^{-1}$ and decreased to $40-80 \mathrm{mg} \mathrm{L}^{-1}$ in the diluate: $80 \%$ of the nitrate migrated from the feed to the product and the brine (Fig. 5C). In one hour, in $20 \mathrm{~L}$, about 7.0 grams of nitrate-N is added to the system, while 1 gram is lost via its bleed. In the meantime, \pm 4 grams are recovered in $5 \mathrm{~L}$ of brine and \pm 2 gram is lost with the bleed of the product.

As in the previous case potassium exclusively accumulates in the brine, where concentrations of $4.5 \mathrm{~g} \mathrm{~L}^{-1}$ are reached; Fig. 5D. With an average current efficiency of $70 \%, 75 \%$ of the potassium that is fed to the system in $20 \mathrm{~L}$ and in $1 \mathrm{~h}(30 \mathrm{~g})$ is recovered in $5 \mathrm{~L}$ of the brine $(22.5 \mathrm{~g})$.

The phosphate-P concentration in the feed is stable around $55 \mathrm{mg} \mathrm{L}^{-1}$ and decreases to somewhat less of half this value in the circulating diluate and the corresponding bleed (Fig. 5E). The MVA membrane does not allow phosphate migration since no phosphate is found in the brine. The phosphate-P concentration in the product varies a bit with the irregularities in the feed (which was interrupted at 120 and $240 \mathrm{~h}$ ) but reaches values as high as $120-140 \mathrm{mg} \mathrm{L}^{-1}$. Under a stable steady state situation $57 \%$ of the phosphate that is added to the system in one hour (1.1 gram) is recovered in the bleed of the product vessel ( 0.65 gram).

With the PC-Acid 100 OT membrane the sulphate concentration in the product constantly increases during the experiment to a value of more than $100 \mathrm{mg} \mathrm{L}^{-1}$. In contrast to phosphate, sulphate migrated to some degree through the PC-MVA membrane, especially at the end of the experiment; Fig. 5F.

The calcium concentration in the feed varies between 40 and $80 \mathrm{mg} \mathrm{L}^{-1}$ and decreases to 10 to $20 \mathrm{mg} \mathrm{L}^{-1}$ (Fig. $5 \mathrm{G}$ ). The calcium concentration in the brine initially is zero and continually increases to values as high as $360 \mathrm{mg} \mathrm{L}^{-1}$.

The magnesium ions perfectly behave as expected; Fig. $5 \mathrm{H}$. The concentration in the brine steadily increases up to about 180 $\mathrm{mg} \mathrm{L}^{-1}$ and stays low and constant in the product, where the magnesium probably arises from a contamination of the sodium chloride used.

In contrast to Exp. 1B with PC-SA membranes, with the PC-Acid OT 100 membranes in place, virtually no DIC migrates to the brine (Fig. 5I). With a current efficiency of about $13.4 \%$ which is somewhat higher than with the PC-SA membrane, a steady state situation arises with about $200 \mathrm{mg} \mathrm{L}^{-1}$ DIC in the product stream.

In the period between the two interruptions in the feed $500 \mathrm{mg}$ TOC is added to the system in one hour from which $75 \mathrm{mg}$ ends in the bleed of the product and about $10 \mathrm{mg}$ is lost in the bleed of the brine; Fig. 5J. This TOC, especially in the product, gave rise to a light-yellow colour.

The phosphate concentration in the product of the aSED was, in contrast with in Exp. 1B, high and stable enough (120-140 mg $\mathrm{L}^{-1}$ ) for further processing. The bleed of the product $\left(5 \mathrm{~L} \mathrm{~h}^{-1}\right)$ was directed to a lamella separator to which also a solution of $\mathrm{CaCl}_{2}$ was added. At the high $\mathrm{pH}$ of the bleed and to minimize calcium carbonate precipitation the adopted $\mathrm{Ca} / \mathrm{P}$ ratio in the separator was kept low at \pm 1.90 (Meesschaert et al., 2020; Monballiu et al., 2018a). If the volumes of the mixing compartment (5.8 L) and the settling tank (25 L) of the lamella separator are taken into account the respective hydraulic retention times are 0.9 and $5.0 \mathrm{~h} .98 \%$ of the phosphate-P was removed from the bleed. The colour that was present in the product stream stayed in solution and the fluffy precipitate settled slowly; Fig. 6 . The isolated product was thoroughly washed with RO water and dried, first in air, later at $105{ }^{\circ} \mathrm{C}$. Ion chromatographic (IC) analysis showed that the precipitate did not contain magnesium, ammonium or potassium. Unfortunately, the amount of carbonate in the precipitate could not be determined, neither by IC nor as DIC. This is on the one hand because acid is necessary to get the precipitate dissolved, which thus set the carbonates free, and on the other hand that carbonate buffers are used during IC.

The $\mathrm{Ca} / \mathrm{P}$ ratio in the dry precipitate was 2.31 , which is too high for calcium phosphate or hydroxyapatite which have respectively $\mathrm{Ca} / \mathrm{P}$ ratios of 1.5 and 1.66. XRD showed the presence of impure hydroxyapatite $(2 \Theta: 32)$ as seen before (Meesschaert et al., 2020) but also of calcite $(2 \Theta=28)$; Fig. 7 .

\subsubsection{Experiment 3: effect of intermittent CIP and aeration of the feed}

In three successive runs that were interrupted by a CIP the effect of that CIP and of aerating the feed was studied. Intermittent CIP had a positive effect on the performance of the equipment. Instead of after two weeks, hydrodynamic problems occurred only after three weeks of operation. The behaviour of the different ions was similar to in Experiment 2. The time course of the most important ions is given in Fig. 8. 


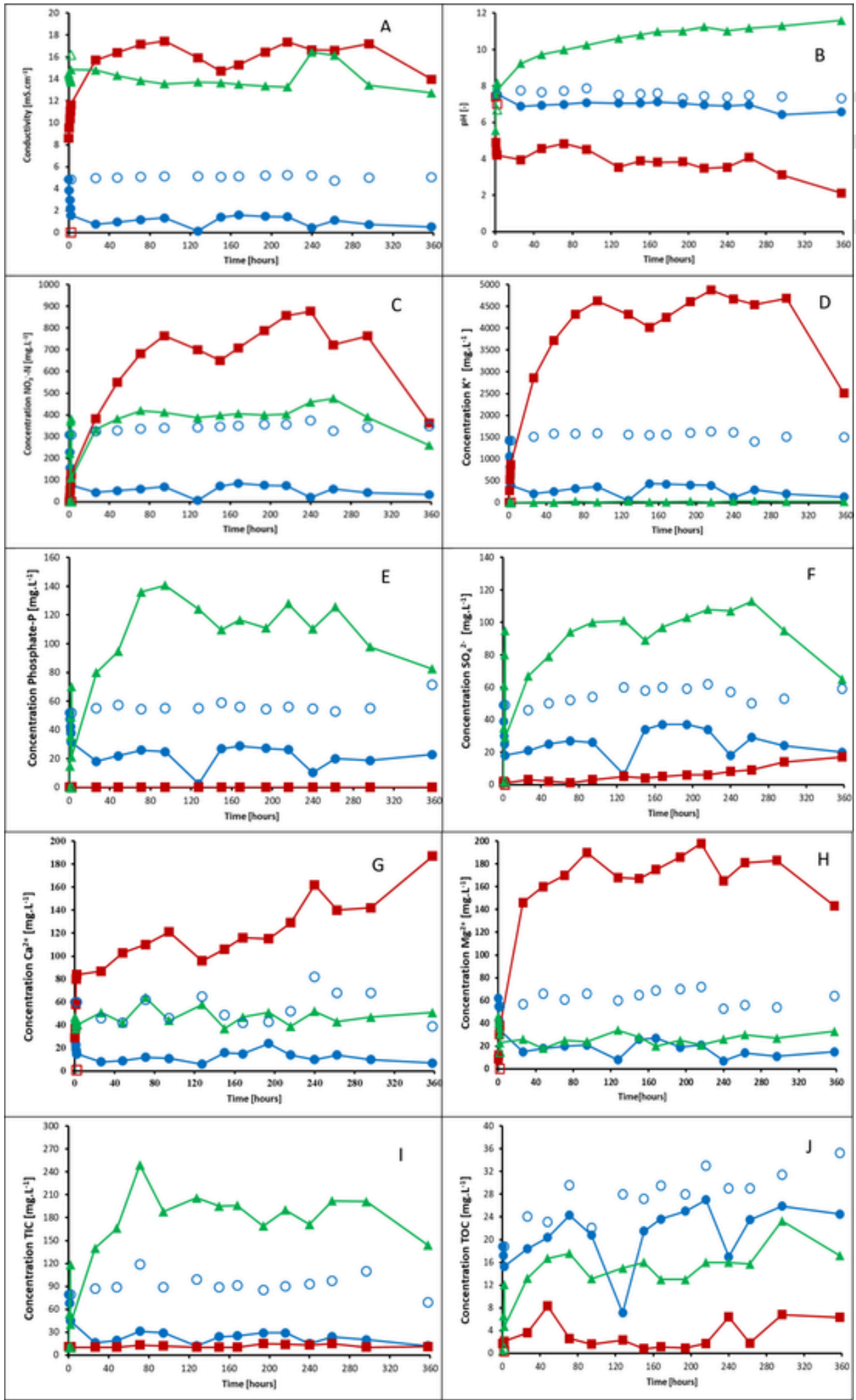

Fig. 5. Results obtained during Experiment 2 with PC-Acid 100 OT/PC-MVA/PC-SC membranes. As function of the time course of the experiment: Fig. 5A gives the conductivity, Fig. 5B the pH, Figs. 5C, 5D, 5E, 5F, 5G, 5H and 5I give respectively the course of the concentration of the following ions: nitrate, potassium, phosphate, sulphate, calcium, magnesium and total inorganic carbon (DIC). Fig. $5 \mathrm{~J}$ gives the course of total organic carbon (TOC). Symbols as in Fig. 3. 


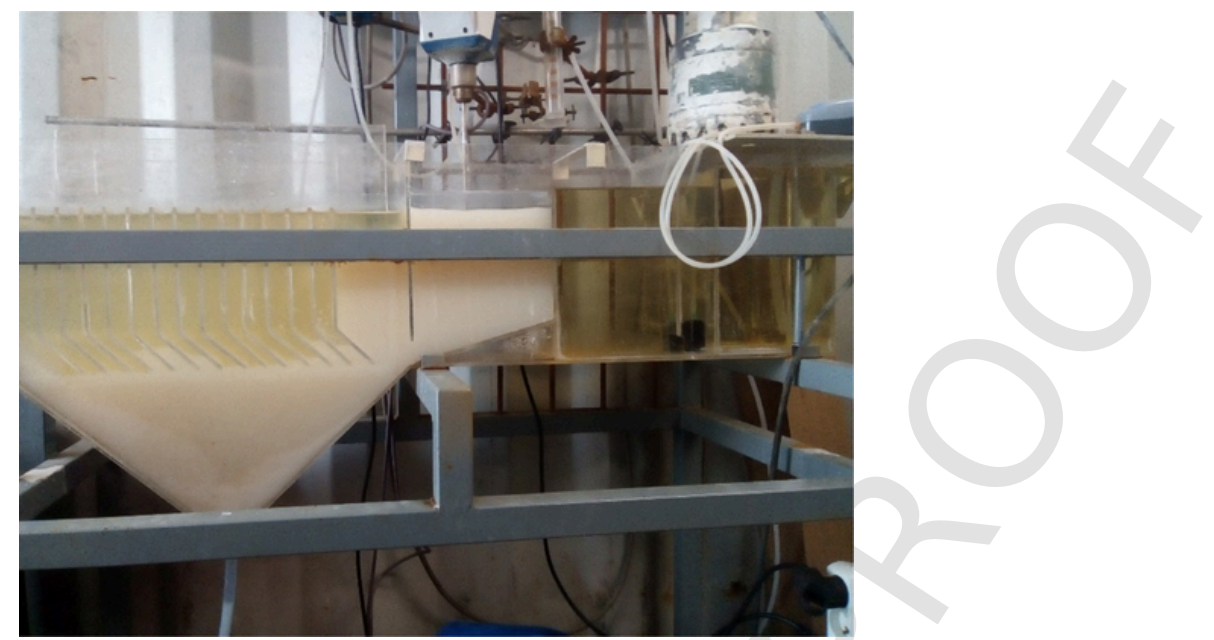

Fig. 6. Recovery of phosphate as calcium phosphate by precipitation in a lamella separator. The calcium chloride solution was dripped to compartment before the settling tank.

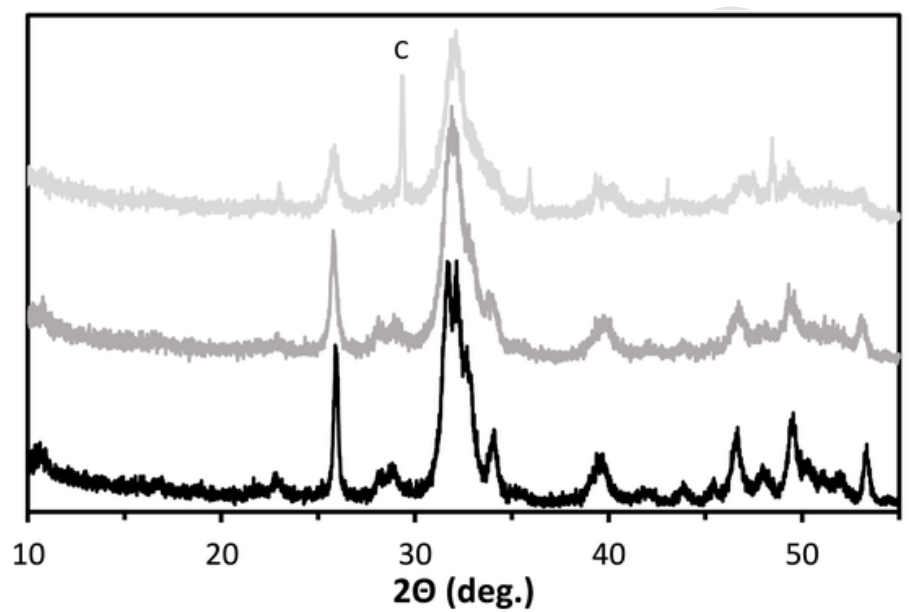

Fig. 7. XRD spectra of the precipitates recovered from Experiment 2 (feed is not aerated - light grey - at the top. C: calcite), Experiment 3 A (feed is aerated with a pond aerator - grey - in the middle) and Experiment 3B (feed is aerated with compressed air - black - at the bottom).

The aeration was entered as a possible way to reduce the amount of DIC. In the previous Experiment 2, the initial DIC of the feed was about $90 \mathrm{mg} \mathrm{L}^{-1}$ (Fig. 5I). By aeration with a pond aerator (Exp. $3 \mathrm{~A}$ ) and with compressed air (Exp. 3B and C) the DIC concentration respectively was reduced to about 51 and $43 \mathrm{mg} \mathrm{L}^{-1}$ (Table 3 and Fig. 8F). This lower value in the feed resulted in reduced DIC values in the product stream, which respectively were 87 and $82 \mathrm{mg} \mathrm{L}^{-1}$ and which are thus considerably lower than in the product obtained without aeration of the feed, where it was about $200 \mathrm{mg} \mathrm{L}^{-1}$; see Fig. $5 \mathrm{I}$. As in Exp. 2, the pH in the diluate reached values of 11-12 and the amount of DIC that was further transported to the brine was neglectable. At the end of Experiment $3 \mathrm{C}$ the DIC values in the feed were very high (about $200 \mathrm{mg} \mathrm{L}^{-1}$ ) which was due to a failing nitrification.

The respective decreases of the conductivity of the feed of 75, 79 and 80\% (Fig. 8A) over the Experiments 3 A-C, show that aeration to remove DIC has a slight but consistent effect on the migration of the ions and thus on the desalination. Indeed, without aeration of the feed the conductivity decreased only by $70 \%$.

Chloride, nitrate-N and potassium (Figs. 8B-D) accumulated in the brine at concentrations of respectively about $4000 \mathrm{mg} \mathrm{L}{ }^{-1}, 1200$ $\mathrm{mg} \mathrm{L}^{-1}$ and $5600 \mathrm{mg} \mathrm{L}^{-1}$. The concentrations for nitrate-N and potassium are higher than in Experiment 2, where they are respectively $900 \mathrm{mg} \mathrm{L}^{-1}$ and $4500 \mathrm{mg} \mathrm{L}^{-1}$.

The phosphate concentration that was reached in the product was $175 \mathrm{mg} \mathrm{L}^{-1}$ phosphate-P $\left(5.6 \mathrm{mmol} \mathrm{L}^{-1}\right.$ phosphate-P). This result was obtained in the three phases of Experiment 3 (Fig. 8E) and is better than in Experiment 2 were the maximum was 120 mg $\mathrm{L}^{-1}$.

The bleed of the product vessel in this third experiment was also directed to the lamella separator for phosphate recovery as calcium phosphate. The recovered precipitate was also free of magnesium, potassium and ammonium. The Ca/P ratio decreased from 2.31 in previous experiment where the feed was not aerated to 1.95 and 1.84 when the feed respectively was aerated with a pond aerator or with compressed air. The precipitate of Experiment 3B appeared crystalline and XRD analysis showed that it contained im- 


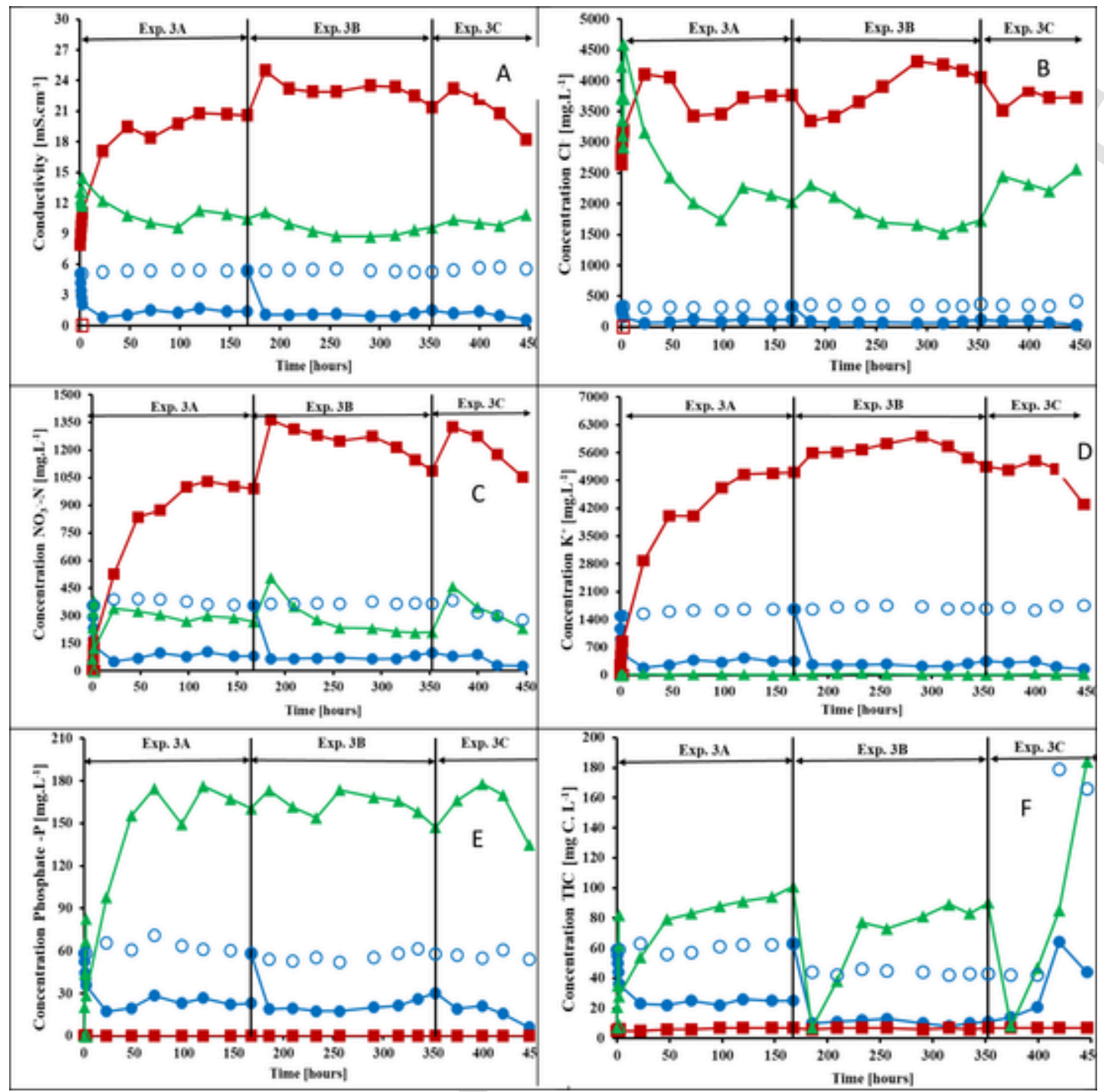

Fig. 8. Results obtained during Experiment 3 using PC-Acid 100 OT/PC-MVA/PC-SC membranes. In run A the feed of the diluate was aerated with a pond aerator; in run $\mathrm{B}$ and $\mathrm{C}$ the aeration was done by compressed air. As function of the time course of the experiment: Fig. 8A gives the conductivity, Figs. 8B, $8 \mathrm{C}$, $8 \mathrm{D}$ and $8 \mathrm{E}$ give respectively the course of the concentration of the following ions: chloride, nitrate, potassium, phosphate. Fig. $8 \mathrm{~F}$ gives the total inorganic carbon (DIC). Symbols as in Fig. 4.

pure hydroxyapatite; see Fig. 7. If all phosphate would be present as hydroxyapatite, it would be responsible for $87 \mathrm{~m} \%$ and $91 \mathrm{~m} \%$ of the precipitate. It is worth mentioning that these XRD's show no obvious signs of the presence of calcite or another crystalline form of calcium carbonate mineral (vaterite, aragonite). The XRD of the precipitate recovered after aeration of the feed with compressed air shows also only impure XRD, but the sharper peaks indicated somewhat more crystallinity than in the precipitate recovered after aeration of the feed with a pond aerator (Meesschaert et al., 2020).

\section{Discussion}

\subsection{Characterization of the feed water}

Seasonal variations in the chemical composition of the potatoes treated are reflected in the composition of the wastewater and explain the large SD values (Table 3). The nitrification consumed a bi-equimolecular amount of DIC and consequently should reduce scaling problems during subsequent selectrodialysis. Because of the intense aeration in the nitrification reactor, most of the organic material (TOC) present in the UASB effluent is oxidized into $\mathrm{CO}_{2}$ and $\mathrm{H}_{2} \mathrm{O}$. This aspect of the nitrification and the fact that ultra-filtration resulted in a further TOC reduction should contribute to reduce fouling problems during selectrodialysis. 


\subsection{Feed and bleed experiments}

Preliminary experiments with the aSED equipment (with PC-SA membranes) in the batch or feed and bleed mode were performed at a vegetable processing plant (D'Arta, Ardooie, Belgium). It became clear that the use of pre-settled, but otherwise untreated UASB effluent as feed water resulted in scaling and (bio)fouling of the diluate circuit (both in the installation and on the membranes) (Ghyselbrecht et al., 2018). The best experiment could only be kept in operation for 3.5 days. The feed had $50 \mathrm{mg} \mathrm{L}^{-1}$ phosphate-P and under a constant current of $2 \mathrm{~A}, 33 \%$ of the phosphate was recovered in the product. All available evidence indicates that phosphate migrates through the anion-exchange membranes as $\mathrm{HPO}_{4}^{2-}$ ions (Ghyselbrecht et al., 2020) and the current efficiency for phosphate transport through the PC-SA membrane according to formula $(1)(n=2)$ was calculated as $0,7 \%$. The current efficiency of DIC and chloride were respectively $38 \%$ and $32 \%$. To reduce the unwanted phenomenon of scaling and to improve the current efficiency for phosphate, a nitrification was implemented on a similar UASB effluent of a potato processor (Agristo, Wielsbeke, Belgium). With pre-settled and nitrified UASB effluent it was possible to enlarge the experiment to about 7 days but mucus still developed in the entire system. The current efficiency of DIC and chloride were $10 \%$ and $14 \%$ respectively, but that of nitrate was $50 \%$; simultaneously the current efficiency of phosphate was 4\%. After nitrification, DIC and chloride thus were less involved in current transport over the anion-exchange membrane; the latter was mainly realized by nitrate while also phosphate $\left(\mathrm{HPO}_{4}^{2-}\right)$ contributed substantially more. In a further attempt to enlarge the continuous process an UV C protection was installed to prevent fouling and this in combination with UV C protection on different circulating liquids to prevent bio-fouling as described above; see Figs. 1 and 2.

\subsubsection{Experiment 1}

The current efficiency of phosphate transport through the PC-SA membrane $(1,7 \%)$ in Experiment 1 A was lower than in the preliminary experiment mentioned above. This is more than likely due to the fact that the concentration of the different monovalent charged anions was significantly higher. The results of Experiment $1 \mathrm{~A}$ indicate that the behaviour of anions and cations is mostly explained by the fact that for each compartment of the stack electroneutrality is required. Positive ions (Ca2+, $\mathrm{Mg} 2+$; Figs. 3F and 3G) in the product are blocked between the two anion-exchange membranes (PC-SA and PC-MVA) and electroneutrality e.g. after entering of phosphate and sulphate ions, can only be realized by expulsion of other anions to the brine, e.g. of chloride ions; Fig. 3D. This required electroneutrality explains also the behaviour of the nitrate ions; Fig. 3E. After an initial phase where the nitrate accumulates in the product, near the end of the experiment when the concentration of chloride in the product is already considerably decreased, nitrate ions are also expelled to the brine to maintain electroneutrality.

Experiment $1 \mathrm{~A}$ shows that it is possible to concentrate phosphate with aSED even at a low current efficiency and even in the presence of a rather high positive concentration gradient (Fig. 3A) and further illustrates that DIC accumulates to a large excess in the product (Fig. 3B). Respectively $66 \%$ and $77 \%$ of the potassium and nitrate- $\mathrm{N}$ is removed from the feed and accumulates in the brine to respectively 2.3 and 3 times their original concentration in the feed (Fig. $3 \mathrm{H}$ and $3 \mathrm{E}$ ). Using a relative flow rate of the feeds (and bleeds) to the feed and the brine of 4 it is thus possible to double the concentration of nitrate and potassium in the brine relative to what they are in the feed which is in agreement with the fact that more than $50 \%$ of the nitrate and potassium are recovered from the feed. As it is also the final goal to recover at least half of the phosphate from the UASB effluent while at least doubling its concentration in the product stream, the same flow rate of the feed (and bleed) of $5 \mathrm{~L} \mathrm{~h}^{-1}$ was adopted for the product in Experiment $1 \mathrm{~B}$.

In Experiment 1B a good desalination of the feed is obtained. It is obvious that decreasing the net feed and bleed diluate flow rate over the stack or increasing the number of triplets or of the surface of the membranes would result in a higher or even complete desalination. This type of water is e.g. suited as cooling water for the condensers of the many cool installations that are in use in vegetable and potato processing companies. The suggested combination of UF and aSED can thus be useful for water reclamation.

The behaviour of most of the ions in Experiment $1 \mathrm{~B}$ was as expected. For most chemical parameters the sum of the amounts found in the bleed of the diluate, product and brine corresponded with the amount introduced in the system via the feed to feed/diluate vessel. This was not the case for calcium, phosphate, DIC and sulphate which indicated that precipitations took place.

In the phase of stable operation, in $1 \mathrm{~h}$ about 5 gram of nitrate- $\mathrm{N}$ is fed to the diluate vessel, and about $2.5,1.5$ and 1 gram leave the system via respectively the bleeds of the brine, the product and the diluate. $50 \%$ of the Nitrate- $\mathrm{N}$ is thus recovered (Fig. $4 \mathrm{C}$ ). Simultaneously $66 \%$ of the potassium is recovered (Fig. 4F). The set goal for $\mathrm{N}$ and $\mathrm{K}$ is thus obtained. The maximum concentration of phosphate obtained in the product was about the same as in the feed, which is far from the set goal of obtaining at least the double concentration; Fig. 4I. The decrease in the concentration of phosphate in the product stream cannot be explained by migration of the phosphate to the brine stream as the concentration in the latter stays zero.

The rather high calcium concentration $\left(115-135 \mathrm{mg} \mathrm{L}^{-1}\right)$ in the feed of the product vessel $(0.15 \mathrm{M} \mathrm{NaCl})$ and of the brine $(0.075$ M) was not expected; Fig. 4G. The process water to prepare the salt solution is RO water that is supplemented with tap water to fulfil all the water needs of the company. Apparently, at the moment of this Experiment $1 \mathrm{~B}$ the process water contained a relative high amount of tap water. And although the product stream circulates in the stack between two anion selective membranes it is seen that the concentration of e.g. calcium drops from $115-135 \mathrm{mg} \mathrm{L}^{-1}$ to $60-90 \mathrm{mg} \mathrm{L}^{-1}$ and it is thus obvious that other processes occur.

The decrease in the phosphate concentration in the product phase after $125 \mathrm{~h}$ can be explained by precipitation as calcium phosphate as simultaneously the mentioned drop of the calcium concentration is noticed (Fig. 4G). This simultaneous reduction of the phosphate and calcium concentration was not seen in Experiment 1 A were the calcium concentration was only $40-50$ mg $\mathrm{L}^{-1}$.This calcium phosphate precipitation in the product stream may have contributed to the scaling of the diluate compartment of the stack. Indeed, the hydraulic resistance of the diluate in the stack increased since the flow rate gradually decreased to $280 \mathrm{~L} \mathrm{~h}^{-1}$. Especially the PC-SA membrane may be susceptible for scaling since this is the membrane where phosphate encounters calcium ions of the 
product stream. After $125 \mathrm{~h}$ the phosphate removal from the diluate virtually stopped, probably as a result of this scaling of the PC-SA membrane. Increasing the current to $2 \mathrm{~A}$ (after $340 \mathrm{~h}$ ) partly restored the phosphate transport over the PC-SA membrane; Fig. 4I.

The feed to the product contained some sulphate $\left(30 \mathrm{mg} \mathrm{L}^{-1}\right.$; Fig. $\left.4 \mathrm{~J}\right)$ and this complicates the interpretation of the results, since apparently more sulphate is entering the product stream via its feed than by migration through the PC-SA membrane. The sulphate concentration of the product is a bit varying but has in general not the tendency to increase or decrease. In the beginning, the concentration in the brine is higher than in the feed to the brine, which may be indication for sulphate migration from the product through the MVA membrane to the brine. Later, the sulphate concentration in the brine decreases, which may then be an indication for sulphate precipitation e.g. as calcium sulphate.

As observed before (Zhang et al., 2013; Ghyselbrecht et al., 2020), most of the DIC accumulates in the product and not in the brine; Fig. 4K. The MVA membrane thus largely prevents the transport of DIC. Since the pH of the product is about 7.5, this DIC occurs as bicarbonate $\left(\mathrm{HCO}_{3}^{-}\right)$, a monovalent anion that normally should migrate through the MVA membranes. This is not the case for HCO $\overline{3}$ as a result of its high ionic radius (Ghyselbrecht et al., 2020). The decreasing DIC concentration in the product at the end of the experiment (Fig. 4K) may indicate calcium carbonate scaling since also the calcium concentration decreases (Fig. 4G).

The transport of TOC to the product and the brine is limited which however does not exclude that organic material may have contributed to fouling of the membranes.

The above results show that the PC-MVA membranes are behaving properly and prevent the migration of bivalent anions also in extended experiments. It is however also obvious that the PC-SA membranes do not allow enough transport of the same bivalent anions. These membranes act themselves already as a kind of monovalent selective membranes as they allow much better transport of monovalent anions than bivalent ions. This observation can also be made clear by calculating the current efficiency of each individual ion by formula (1). The results are summarized in Table 4. The current efficiency of TOC cannot be calculated as its structure is not known. From Table 4 it is obvious that, with $54.8 \%$ of the consumed current, $\mathrm{K}+$ is carrying most of the current over the PC-SC membrane. Nitrate appears to play an important role in carrying current over the PC-SA membrane: it is responsible for about one third of the current. The current efficiency for phosphate transport is only about 1.1\% (mean value) while the value for DIC transport is $10 \%$.

A good standard anion exchange membrane would be a membrane which does not make any difference in its permeability for monovalent and bivalent anions. This was the reason to investigate, first in batch modus and on lab scale and later also on pilot scale, the use of other anion exchange membranes for their use as standard anion exchange membrane in an aSED stack (Ghyselbrecht et al., 2020). This study revealed that the PC-Acid 100 OT membrane from the same provider (PCA, Germany) and mountable in the same stack should perform better than the PS-SA membrane. In the following section this PC-Acid 100 OT membrane is therefore fully tested in log-term experiments in the feed and bleed modus. From the results presented above it is further also obvious that all possible measures must be taken to avoid calcium ions in the product and brine streams. Consequently, in the following experiments pure RO-water and extra pure sodium chloride were used to prepare the initial liquids for the product and brine vessels and for the feed of these two vessels.

\subsubsection{Experiment 2}

The decrease in conductivity during Experiment 2 was similar to that observed during Experiment 1B. On the contrary, whereas almost no effect on the $\mathrm{pH}$ was observed in Experiment 1B, the $\mathrm{pH}$ of the product significantly increased during Experiment 2 . This $\mathrm{pH}$ increase with this type of membrane was seen before (Ghyselbrecht et al., 2020). The migration of $\mathrm{HPO}_{4}^{2-}$ through SA membranes goes in combination with an acidification of the diluate and the brine and a simultaneous alkalinization of the product stream (Ghyselbrecht et al., 2020). At the end of the experiment a minor part of the phosphate is present as trivalent $\mathrm{PO}_{4}^{3-}$ ion since the pKa3 of phosphoric acid is 12.32. This $\mathrm{pH}$ increase should facilitate the precipitation of phosphate from this product stream, but will also facilitate the precipitation of calcium carbonate.

Respectively $57 \%$ of the nitrate and $75 \%$ of the potassium are recovered in the brine, which is better than with the PC-SA membrane where it was respectively $50 \%$ and $66 \%$. The current efficiency of nitrate over the PC-Acid 100 OT membrane increased by about $15 \%$ (Table 4).

With the PC-Acid100 OT membrane $57 \%$ of the phosphate was recovered and the set goal for this nutrient was thus also obtained. The current efficiency for phosphate transport over anion selective membrane is 4.5 times better than with the PC-SA membrane (Table 4). The better transport of phosphate through the Acid 100 OT membrane is apparently due to the bigger pore sizes of the

Table 4

Average current efficiency of the different ions under the varying experimental conditions: Exp 1B: using the SA/MVA/SK combination without aeration of the feed; Exp. 2 and 3A with the ACID 100 OT/MVA/ SK combination of membranes, respectively without aeration and with aeration with a pond aerator.

\begin{tabular}{|c|c|c|c|c|c|c|c|}
\hline \multicolumn{8}{|c|}{ Current efficiency of the different ions } \\
\hline \multicolumn{4}{|c|}{ Cations } & \multicolumn{4}{|l|}{ Anions } \\
\hline & Exp. 1B & Exp. 2 & Exp. 3A & & Exp. 1B & Exp. 2 & Exp. 3A \\
\hline $\mathrm{Na}^{+}$ & 0.050 & 0.032 & 0.032 & $\mathrm{Cl}^{-}$ & 0.166 & 0.154 & 0.163 \\
\hline $\mathrm{K}^{+}$ & 0.548 & 0.703 & 0.890 & $\mathrm{NO}_{3}^{-}-\mathrm{N}$ & 0.383 & 0.529 & 0.528 \\
\hline $\mathrm{Ca}^{2} ?$ & 0.047 & 0.045 & 0.034 & $\mathrm{HPO}_{4}^{2-}-\mathrm{P}$ & 0.011 & 0.050 & 0.070 \\
\hline \multirow[t]{2}{*}{$\mathrm{Mg}^{2+}$} & 0.039 & 0.091 & 0.102 & $\mathrm{SO}_{4}^{2-}$ & 0.005 & 0.013 & 0.028 \\
\hline & & & & $\mathrm{HCO}_{3}^{-}$ & 0.100 & 0.134 & 0.075 \\
\hline
\end{tabular}


membrane which is developed for the transport of sulphate ions in the frame of sulphuric acid production in combination with bipolar membranes [personal communication by PCA]. The latter point is also reflected by the migration behaviour of sulphate through the different membranes acting as anion-exchange membrane; as can be seen by comparing Fig. $4 \mathrm{~J}$ and $5 \mathrm{~F}$.

The concentration of calcium in the product is about $50 \mathrm{mg} \mathrm{L}^{-1}$. As the RO water used to prepare this solution contains no calcium the latter is assigned to be present in the sodium chloride that was used. The fact that the calcium concentration in the product does not change is perfectly normal as calcium circulates between two anion-exchange membranes, but also indicates that there is no calcium precipitation e.g. as phosphate or carbonate. In Experiment $1 \mathrm{~B}$ the calcium concentration was $120 \mathrm{mg} \mathrm{L}^{-1}$ and more than likely caused calcium carbonate, calcium phosphate and eventually calcium sulphate scaling. In Experiment 1 A the calcium concentration in the product was also only about $60 \mathrm{mg} \mathrm{L}^{-1}$ and despite the high phosphate concentrations no signs of calcium phosphate precipitation was observed; Fig. 3A. It is therefore necessary to keep the calcium concentration as low as possible and $50-60 \mathrm{mg} \mathrm{L}^{-1}$ thus appears acceptable. This clear amelioration of the scaling problems did however not prevent that the hydraulic conditions worsened and probably indicates that fouling rests a problem.

Since the $\mathrm{pH}$ in the product increases to values of $11-12$, DIC will largely occur as carbonate $\left(\mathrm{CO}_{3}^{2-} ; \mathrm{pKa}_{2}=10.5\right)$, a bivalent ion that, as expected, cannot permeate through the MVA membrane. DIC may inhibit phosphate recovery as calcium phosphate (Meesschaert et al., 2020; Monballiu et al., 2018a) and other precautions must thus be taken to lower this DIC concentration in the product stream.

Where in the first bleed and bleed experiment virtually no TOC migrated to the product and the brine (Fig. 4L), with this new membrane assembly of Experiment 2 a substantial amount of the TOC migrates to the product and further to the brine (Fig. 5J). This phenomenon is likely due to the larger pores of the PC-Acid 100 OT membranes that facilitate not only the transport of phosphate and sulphate ions but also of some negatively charged organic molecules.

The phosphate from the product of aSED could be recovered nearly quantitatively. The recovered precipitate was free of magnesium and other metal ions. The absence of this ions is evident as these cations are directed to the brine stream during aSED. Contamination with magnesium is often a problem when phosphate is directly precipitated from wastewater as calcium phosphate since magnesium phosphate and calcium phosphate are behaving very similar (Meesschaert et al., 2020; Monballiu et al., 2018a). The approach of recovering phosphate as calcium phosphate via an intermediate aSED is thus very promising when one wants to recover phosphate that is free from other metal ions.

At the actual pH of about 11 (Fig. 5B), a DIC concentration of about $250 \mathrm{mg} \mathrm{L}^{-1}\left(=20 \mathrm{mmol} \mathrm{L}^{-1}\right.$; Fig. 5I) and a phosphate-P concentration of about $120 \mathrm{mg} \mathrm{L}^{-1}\left(4 \mathrm{mmol} \mathrm{L}{ }^{-1}\right.$; Fig. $\left.5 \mathrm{E}\right)$ it is obvious that both calcium carbonate and calcium phosphate precipitate. In the idea that phosphate precipitated as calcium phosphate and that it is only contaminated with calcium carbonate, from the Ca/P ratio of 2.31, it can be calculated that about $66 \mathrm{~m} \%$ of the precipitate is calcium phosphate. The phosphate amount was equivalent to $30.3 \mathrm{~m} \% \mathrm{P}_{2} \mathrm{O}_{5}$ (determination by Prayon, Engis, Belgium), which perfectly matches with the calculated content of calcium phosphate and proves that this type of precipitate just consists out of calcium phosphate and calcium carbonate.

\subsubsection{Experiment 3}

Aeration of nitrified UASB effluent result is a shift of bicarbonate alkalinity into hydroxide alkalinity and the expulsion of carbon dioxide. This DIC removal finally resulted in a halved value of the current efficiency for DIC transport: as well in Experiment 3 A as in Experiment 3B: it was 0.075 where it was 0.134 in Experiment 2 (Table 4). This indicates that less current is wasted for DIC transport. During the time course of the aSED experiments the global conductivity also decreased more when the feed was previously aerated: $75-80 \%$ versus $70 \%$.

The behaviour of the chloride ion, as can be seen in Fig. 8B, agrees with the basic concept of electroneutrality. The more phosphate accumulates in the product the more chloride is driven to the brine; the final concentration is $3500-4500 \mathrm{mg} \mathrm{L}^{-1}$. By optimizing the chloride concentration in the initial product and brine solutions and in the feeds to the product and brine vessels it is possible to reduce its final concentration in the brine. This would be beneficiary in view of the possible application of the brine as N/K fertilizer.

The most important solutes of the brine e.g. for Experiment 3B are nitrate ( 1.26 nitrate- $\left.\mathrm{N} \mathrm{g} \mathrm{L}^{-1} ; 90 \mathrm{mmol} \mathrm{L}^{-1}\right)$ and potassium $(5.85$ $\mathrm{g} \mathrm{L}^{-1} ; 150 \mathrm{mmol} \mathrm{L}^{-1}$ ); see Figs. 8C and 8D. As such, both nutrients were recovered for more than 80\%. This is better than in Experiment 2 where the yields were $57 \%$ and $75 \%$ for respectively nitrate and potassium. The bleed of the brine which is a lot more concentrated in nutrients than the bleed of the product is in phosphorus, is probably directly useable as $\mathrm{N}$ and $\mathrm{K}$ fertilizer and is completely free of $\mathrm{P}$. This can be very interesting for these cases were the use of P-containing fertilizers is forbidden. As it is now, the high concentration of chloride which reaches values of $3500-4500 \mathrm{mg} \mathrm{L}^{-1}\left(100-125 \mathrm{mmol} \mathrm{L}^{-1}\right)$ is a disadvantage; Fig. 8B. But as discussed, a further refinement of the experimental conditions may lead to a reduction of the chloride concentration of the brine. The fact that the role of chloride in maintaining electroneutrality can be taken over by nitrate as observed in Experiment $1 \mathrm{~A}$ is an important observation in this context.

The current efficiencies for each of the ions is listed in Table 4 for the feed that was aerated with the pond aerator (Exp. 3 A). The effect of this decreased DIC concentration on the transport of the other anions is clear. Table 4 shows that the current efficiency of the bivalent anions increased: the current efficiency for respectively sulphate and phosphate increased from 0.013 and 0.050 to 0.028 and 0.070 . The lower DIC concentration had no effect on the current efficiency of nitrate. It possibly can be argued that nitrification creates extra anions that come in competition with phosphate for transport to the anode. It is in this context important to observe that the migration of phosphate is not influenced by nitrate, while it is influenced by the transport of bicarbonate. It is also worth mentioning that in the preliminary experiment in which no preceding nitrification was done, the current efficiency of phosphate was 
only $0.7 \%$. Although that in these exploratory experiments the PC-SA/PC-MVA/PC-SC combination of membranes was used, the low current efficiency of phosphate was apparently partly due to the very high DIC concentration in untreated UASB effluent (Table 3).

A positive effect of aeration of the feed on the migration of phosphate through the PC-Acid 100 OT membrane is thus observed and is reflected by the higher phosphate concentration in the product $\left(175 \mathrm{mg} \mathrm{L}^{-1}\right)$; Fig. 8E. Over the Experiments 2 , $3 \mathrm{~A}$ and $3 \mathrm{~B}$, the degree of migration of phosphate from the diluate to the product increased from $57 \%$ when there is no aeration of the feed to $62 \%$ and 64\% with increasing degrees of aeration. Although the degree of phosphate removal from the feed is lower than the degree of desalination, it is obvious that almost complete phosphate removal can be obtained when enough membrane surface would be used or if a lower flow rate over the stack would be applied. In this context it is also important that no phosphate is detected in the brine. The MVA membranes are thus working perfectly.

As in the case of Experiment 2 the precipitated calcium phosphate from Experiments $3 \mathrm{~A}$ and $3 \mathrm{~B}$ is more than likely only contaminated with calcium carbonate. The calcium phosphate content of the precipitates is calculated respectively as $77 \mathrm{~m} \%$ and $82 \mathrm{~m} \%$; this is equivalent to a $\mathrm{P}_{2} \mathrm{O}_{5}$ concentration of 35 and $38 \mathrm{~m} \%$. The XRD showed a somewhat larger crystallinity for hydroxyapatite but in contrast to what was the case for the precipitate of Experiment 2 no crystalline calcite was detected. This agrees with the calculated lower contamination with calcium carbonate.

\subsubsection{General discussion}

The calcium carbonate present forms a problem when the precipitate would be used in the wet method for phosphoric acid production (Li et al., 2020). In this method sulphuric acid is used to convert calcium phosphate to phosphoric acid and as such extra acid would be necessary to neutralize the calcium carbonate, which in this case would be accompanied by gas formation $\left(\mathrm{CO}_{2}\right)$ and foaming. The latter problem can eventually be circumvented by a previous calcination of the precipitate but would not influence the extra consumption of acid as the formed calcium oxide must also be neutralized.

As stated above, the application of aSED on nitrified UASB effluent to fractionate and concentrate phosphate in the product also results in a purification since the phosphate is separated from cations (that move to the brine). Apart from the contamination with calcium carbonate the calcium phosphate is free from metals. Further research can concentrate on the removal of all the DIC from the feed to the aSED. This is easily done by aeration under $\mathrm{pH}$ stat conditions (Zhang et al., 2011). In this way virtually pure calcium phosphate can be obtained which would be suitable for the preparation of pure white phosphorus $\left(\mathrm{P}_{4}\right)$. White phosphorus is a critical element which itself has to do with the fact that mined phosphorus is increasingly contaminated with radioactive elements and heavy metals. At the world water congress in Tokyo in 2018 prof. Ohtake proposed to rethink the process of phosphate recovery in function of the production of white phosphorus (Ohtake, 2018).

For the recovery of phosphate from nitrified UASB effluent it was previously calculated that the global cost is about the same as removal with ferric chloride with however this advantage that the phosphate is not only removed but also recovered (Meesschaert et al., 2020). Considering the working conditions ( $25 \mathrm{~V}$ and $1 \mathrm{~A}$ or $25 \mathrm{Wh}$ consumption in $1 \mathrm{~h}$ ) of the pilot scale aSED equipment, a price for electricity of $0.075 € / \mathrm{kWh}$ and the net feed rate of pre-treated UASB effluent $\left(20 \mathrm{~L} \mathrm{~h}^{-1}\right)$, the cost for electricity consumption related to the stack to treat $1 \mathrm{~m}^{3}$ water is about $€ 0.09$. In $50 \mathrm{~h}$, from every $\mathrm{m}^{3}$ pre-treated UASB effluent $35 \mathrm{~g}$ phosphate-P is fractionated in the product stream of the aSED. The corresponding cost to fractionate $1 \mathrm{~kg}$ phosphate-P in the product is thus about $€ 2.7$. In the described feed and bleed mode of operation of the pilot stack, the energy consumption for pumping the liquids is estimated as being approximately 4 times higher than the electricity cost for the stack, resulting in a total rough estimate of $0.5 € / \mathrm{m}^{3}$ or $13 € /(\mathrm{kg}$ phosphate-P). In a once through mode of operation the cost to pump the liquid to be treated through the aSED stack would be lower. It is however obvious that the fractionation and preconcentration with aSED causes an extra cost. It makes that this kind of combination of technologies can only be economically viable when the recovered calcium phosphate can be converted to a very valuable product such as the above mentioned white phosphorus.

During the experiments of 2 to 3 weeks there were no obvious signs of biofouling of the system. There was no development of mucus in the diluate vessel and other visible parts of the equipment. This is contrary to what happened in the preliminary experiment where the nitrification, the ultra-filtration and the UV C protection were not yet implemented. The same was also valid in an experiment in which the nitrification was already active but in which the ultrafiltration and UV-C treatment of the circulating fluids was not yet implemented and which could only last for one week. As such, this ultra-filtration and UV C protection, appeared as indispensable, although it apparently did not prevent fouling of the membranes, which is in some way expected since UV light only controls bacterial growth in the circulating fluids. The necessity of the UV C treatment has mainly to do with the used feed and bleed system of operation. This system allows to work continuously but has the disadvantage that the content of the vessels is continuously recycled over the stack which gives micro-organisms the time to develop, especially in the feed/diluate vessel. If one would work with a once-through mode of operation, less problems with (bio)fouling would occur. The same can probably be said for scaling problems as crystalline embryos would probably be less retained in the system if a once-through mode of processing would be applied.

Hydraulic problems were highly countered by a nitrification of the feed and the accompanying reduction of the concentration of DIC. To further reduce the chance of scaling, the solutions intended for the product and brine vessel should contain as less calcium as possible. With $50-60 \mathrm{mg} \mathrm{L}^{-1}$ calcium in the product stream, apparently no precipitation occurred where this obviously was the case at a concentration of $120 \mathrm{mg} \mathrm{L}^{-1}$ calcium. With this precaution it was possible to run a continuous experiment for about 2 weeks (Exp. 2) or a semi-continuous experiment for about 3 weeks with a preventive short CIP cleaning every week (Exp. 3).

After Exp. 2 the hydraulic properties of the stack with the PC-Acid 100 OT/PC-MVA/PC-SA could be restored as described, but after the third experiment (in total 5 weeks of operation), the maximally attainable flow rate over the diluate compartments after an extensive CIP was only $350 \mathrm{~L} \mathrm{~h}^{-1}$. This needed rinsing by $12 \% \mathrm{HNO}_{3}(1 \mathrm{~h}), 1 \% \mathrm{NaOH}(1 \mathrm{~h}), 0.5 \mathrm{M} \mathrm{NH}_{3} \mathrm{SO}_{3}(2 \mathrm{~h}), 1 \% \mathrm{NaOH}(18 \mathrm{~h})$ 
and $12 \% \mathrm{HNO}_{3}(18 \mathrm{~h})$ and intermediate double washings steps with $\mathrm{RO}$ water. Rinsing with HNO3was most effective and resulted in foaming. This foaming may indicate that the hydrodynamic problems are caused both by scaling and fouling.

An ultra-filtration of the feed was introduced to reduce the fouling capacity of the nitrified UASB effluent, to remove the latter's turbidity and to maximize the antibacterial effect of the UV C treatment. The UF-filtrate apparently still contains organic material that causes fouling of the membranes. Most organic materials are negatively charged at neutral $\mathrm{pH}$ and so they stick to the standard anion exchange membrane. During normal electrodialysis such a fouling issue is often solved by implementing EDR (electrodialysis reversal), a procedure in which at regular intervals the electrodes are being reversed for a small period to liberate deposits on the membranes (Tanaka, 2015). The fact that the cathode of the stack used for this study is made of stainless steel (that would dissolve if it would be used as anode) however made it impossible to test this approach.

\section{Conclusion}

The reclamation of water and the fractionation and concentration of potassium, nitrate and phosphate $\left(\mathrm{HPO}_{4}^{2-}\right)$ from effluent of an upflow anaerobic sludge blanked reactor (UASB) from a potato processing plant was investigated with anion selectrodialysis (aSED) on pilot scale. The equipment was run in the feed and bleed mode for the fractionation of phosphate in the product stream and for the fractionation of potassium and nitrate in the brine stream.

Nitrification as pre-treatment prior to selectrodialysis was introduced to reduce the concentration of dissolved inorganic carbon (DIC) and scaling problems. In combination with an ultra-filtration (UF) and a UV treatment to prevent fouling and biofouling the operation time could be enlarged from 3.5 days to two weeks. By preventive intermittent cleaning in place (CIP) every week it was also possible to operate the pilot scale system for three weeks. The calcium ion concentration in the circulating product stream should be as low as possible. The UF and aSED combination of purification methods can be an alternative for the more classic UF and reverse osmosis (RO) combination.

In a set up with the PC-SA/PC-MVA/PC-SC membrane combination in which the product vessel operated in batch the phosphate concentration increased 5.6 times relative to the concentration of the feed in 15 days at a specific current for phosphate transport of $1.7 \%$.

With the PC-Acid 100 OT/PC-MVA/PC-SC membrane combination in the full feed and bleed mode the conductivity of the nitrified

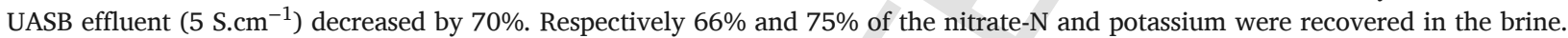
The current efficiency for phosphate transport was $5.0 \%$ and $57 \%$ of the phosphate was recovered in the product stream. The set goal to recover minimum $50 \%$ of the nutrient while simultaneously doubling its concentration was reached for the three nutrients. At a $\mathrm{Ca} / \mathrm{P}$ ratio of $1.93,97 \%$ of the phosphate from the product stream precipitated as calcium phosphate. The recovered precipitate was free of ammonium, potassium and magnesium, but the $\mathrm{Ca} / \mathrm{P}$ ratio of the precipitate $(2.31)$ indicated that it contained $34 \mathrm{~m} \%$ calcium carbonate.

When the feed to the aSED system operating with the PC-Acid 100 OT/PC-MVA/PC-SC membrane combination was first aerated with a pond aerator or by compressed air to blow out part of the DIC, the desalination of the nitrified UASB effluent increased up to $80 \%$. In addition, the current efficiency for DIC transport decreased from $13.4 \%$ to $7.5 \%$ while the current efficiency for phosphate transport increased from 5.0 to $7.0 \%$ and this of nitrate was not affected. More than $80 \%$ of the nitrate-N and of the potassium was recovered in the brine. The precipitates that were recovered from the product stream had lower $\mathrm{Ca} / \mathrm{P}$ ratios of respectively 1.95 and 1.84 and contained the equivalent of $35 \%-38 \% \mathrm{P}_{2} \mathrm{O}_{5}$.

\section{CRediT authorship contribution statement}

Boudewijn Meesschaert: Conceptualization, Funding acquisition, Supervision, Writing - review \& editing. Karel Ghyselbrecht: Investigation, Validation. Annick Monballiu: Investigation, Validation. Luc Pinoy: Conceptualization, Writing - review \& editing.

\section{Declaration of Competing Interest}

The authors declare that they have no known competing financial interests or personal relationships that could have appeared to influence the work reported in this paper.

\section{Acknowledgements}

The authors gratefully acknowledge financial support through the TETRA project "Phosphate Recovery 2.0" (HBC.2017.0029) by the Flanders Agency for Innovation \& Entrepreneurship (VLAIO) . VLAKWA-VITO (Flemish Knowledge Centrum Water - Flemish Institute for Technological research), Belgapom (Professional association of the Belgian Potato Trade and Processing companies) and VeGeBe (Federation of the Belgian Vegetable Processors and Traders in Industrial Vegetables) are acknowledged for their help and encouragement during the project application. D'Arta NV (Ardooie, Belgium) and Agristo NV (Waregem and Wielsbeke, Belgium) are acknowledged for allowing the placement of the pilot installation on site and practical help. We are grateful to Paridaen NV (Oostkamp, Belgium) for practical advice on the use of UV C lamps and pomp aerators. Ekopak NV is acknowledged for the UF unit, which could be used for free. 


\section{References}

[Alvaro et al., 1993] M. Alvaro, M. Esplá, J. Llinares, Matiñez, J. Soto, A small-scale, easy to run waste-treatment plant, J. Chem. Educ. 70 (A129-A132) (1993). [Cisse and Mrabet, 2004] L. Cisse, T. Mrabet, World phosphate production: overview and prospects, Phosphorus Res. Bull. 15 (2004) $21-25$.

[Cordell et al., 2000] D. Cordell, J.-O. Drangert, S. White, The story of phosphorus: global food security and food for thought, Global Environ. Change 19 (2000) 293-305.

[Desmidt et al., 2015] E. Desmidt, K. Ghyselbrecht, Y. Zhang, L. Pinoy, B. Van der Bruggen, W. Verstraete, K. Rabaey, B. Meesschaert, Global phosphorus scarcity and full-scale P-recovery techniques: a review, Crit. Rev. Environ. Sci. Technol. 45 (2015) 336-384.

[Driver et al., 1999] J. Driver, D. Lijmbach, I. Steen, Why recover phosphorus for recycling, and how?, Environ. Technol. 20 (1999) 651-662.

[Fields, 2004] S. Fields, Global Nitrogen: cycling out of control, Environ. Health Perspect. 112 (2004) A556-A563.

[Ghyselbrecht et al., 2012] K. Ghyselbrecht, E.Van. Houtte, L. Pinoy, J. Verbauwhede, B. Van der Bruggen, B. Meesschaert, Treatment of RO concentrate by means of a combination of a willow field and electrodialysis, Resour. Conserv. Recy. 65 (2012) 116-123.

[Ghyselbrecht et al., 2013] K. Ghyselbrecht, M. Huygebaert, B. Van der Bruggen, R. Ballet, B. Meesschaert, L. Pinoy, Desalination of an industrial saline water with conventional and bipolar membrane electrodialysis, Desalination 318 (2013) 9-18.

[Ghyselbrecht et al., 2020] K. Ghyselbrecht, A. Jongbloet, L. Pinoy, B. Meesschaert, Optimization of the configuration of the anion Selectrodialysis stack for fractionation of phosphate from UASB effluent in batch mode on lab scale and pilot scale, J. Environ. Chem. Eng. (2020), doi:10.1016/ j.jece.2020.104.104492.

Ghyselbrecht, K., Monballiu, A., Sansen, B., Ye, Z.L., Pinoy, L., Meesschaert, B., 2018. Fractionation of bivalent ions by selectrodialysis for phosphate recovery. In: IWA World Water Congress \& Exhibition, 16-21 sept, Session TS: Resource Recovery I: Inorganic, Tokyo, Japan.

[Gunther, 1997] F. Gunther, Hampered effluent accumulation process: phosphorus management and societal structure, Ecol. Econom. 21 (1997) 159-174.

Heffer, P.M., Prud'homme, M., 2009. Fertilizer outlook 2009-2013. In: $77^{\text {th }}$ IFA Annual Conference International Fertilizer Industry Association, IFA, Shanghai, China, May 25-27.

[Hell et al., 1998] F. Hell, J. Lahnsteiner, H. Frischherz, G. Baumgartner, Experience with full-scale electrodialysis for nitrate and hardness removal, Desalination 117 (1998) 173-180.

[Jaffer et al., 2002] Y. Jaffer, T.A. Clark, P. Pearce, S.A. Parsons, Potential phosphorus recovery by struvite formation, Water Res. 36 (2002) $1834-1842$.

[Li et al., 2020] H. Li, W. Ge, J. Zhang, R.M. Kasomo, J. Leng, X. Weng, Q. Chen, Q. Gao, S. Song, L. Xiao, C. Tian, Control foaming performance of phosphate rocks used for wet-process of phosphoric acid by phosphoric acid, Hydrometallurgy (2020), doi:10.1016/hydromet.2020.105364.

[Liu et al., 2017] R. Liu, Y. Wang, G. Wu, J. Luo, S. Wang, Development of a selective electrodialysis for nutrient recovery and desalination during secondary effluent treatment, Chem. Eng. J. 322 (2017) 224-233.

[Liu et al., 2016] J. Liu, J. Yuan, Z. Ji, B. Wang, Y. Hao, X. Guo, Concentrating brine from seawater desalination process by nanofiltration-electrodialysis integrated membrane technology, Desalination 390 (2016) 53-61.

[Meesschaert et al., 2020] B. Meesschaert, A. Monballiu, K. Ghyselbrecht, C. Van Goethem, H. Hubert Halleux, L. Pinoy, Pilot scale recovery of phosphorus as calcium phosphate from nitrified UASB effluent of a potato processor and subsequent reuse in the wet process for phosphoric acid production, J. Environ. Chem. Eng. (2020), doi:10.1016/j.jece. 2020.104593.

[Mehta et al., 2015] C.M. Mehta, W.O. Khunjar, V. Nguyen, S. Tait, D.J. Batstone, Technologies to recover nutrients from waste streams: a critical review, Crit. Rev. Environ. Sci. Technol. 45 (2015) 385-427.

[Monballiu et al., 2018a] A. Monballiu, E. Desmidt, K. Ghyselbrecht, B. Meesschaert, The inhibitory effect of inorganic carbon on phosphate recovery from upflow anaerobic sludge blanket reactor (UASB) effluent as calcium phosphate, Water Sci. Technol. 78 (2018a) 2608-2615.

[Monballiu et al., 2018b] A. Monballiu, E. Desmidt, K. Ghyselbrecht, B. Meesschaert, Phosphate recovery as hydroxyapatite from nitrified UASB effluent at neutral pH in a CSTR, J. Environ. Chem. Eng. 6 (2018b) 4413-4422.

[Ohtake, 2018] H. Ohtake, Recovery, reuse of phosphorus from wastewater, Japan Times 122 (42584) (2018).

[Pronk et al., 2006] W. Pronk, M. Biebow, M. Boller, Electrodialysis for recovering salts from a urine solution containing micropollutants, Environ. Sci. Technol. 40 (2006) 2414-2420.

[Reig et al., 2016] M. Reig, C. Valderrama, O. Gibert, J.L. Cortina, Selectrodialysis and bipolar membrane electrodialysis combination for industrial process brines treatment: Monovalent-divalent ions separation and acid and base production, Desalination 399 (2016) 88-95.

[Roeleveld et al., 2004] P. Roeleveld, P. Loeffen, H. Temmink, B. Klapwijk, Dutch analysis for P-recovery from municipal wastewater, Water Sci. Technol. 49 (2004) 191-199.

[Schipper et al., 2001] W.J. Schipper, A. Klapwijk, B. Potjer, W.H. Rulkens, B.G. Temmink, F.D.G. Kiestra, A.C.M. Lijmbach, Phosphate recycling in the phosphorus industry, Environ. Technol. 22 (2001) 1337-1345.

[Strathmann, 2010] H. Strathmann, Electrodialysis, a mature technology with a multitude of new applications, Desalination 264 (2010) $268-288$.

[Tanaka, 2015] Y. Tanaka, Chapter 16: Electrodialysis reversal, Ion Exchange Membranes: Fundamentals and Applications, second ed., Elsevier, 978-0-444-63319-4, 2015.

[Tran et al., 2014] A. Tran, Y. Zhang, D.De. Corte, J. Hannes, W. Ye, P. Mondal, N. Jullok, B. Meesschaert, L. Pinoy, B. Van der Bruggen, P-recovery as calcium phosphate from wastewater using an integrated selectrodialysis/crystallization process, J. Cleaner Prod. 77 (2014) $140-151$.

[Tran et al., 2015] A. Tran, Y. Zhang, J. Lin, P. Mondal, W. Ye, B. Meesschaert, L. Pinoy, B. Van der Bruggen, Phosphate pre-concentration from municipal wastewater by selectrodialysis: effect of competing components, Sep. Purif. Technol. 141 (2015) 38-47.

[Van Vuuren et al., 2010] D.P. Van Vuuren, A.F. Bouwman, A.H.W. Beusen, Phosphorus demand for the 1970-2100 period: a scenario analysis of resource depletion, Global Environ. Change 20 (2010) 428-439.

[Venugopalan, 2015] H. Venugopalan, UVC LEDs for biofilm prevention, Water online, Guest column, August 4, 2015.

[Ward et al., 2018] A.J. Ward, K. Arola, E.T. Brewster, C.M. Mehta, D.J. Batstone, Nutrient recovery from wastewater through pilot scale electrodialysis, Water Res. 135 (2018) 57-65.

Yakovleva, N., 2017. Potassium fertilizer and development: review of major approaches to improve supply. In: $2^{\text {nd }}$ International Workshop on Alternative Potash, London, 15 June.

[Zhang et al., 2013] Y. Zhang, E. Desmidt, A. Van Looveren, L. Pinoy, B. Meesschaert, B. Van der Bruggen, Phosphate separation and recovery from wastewater by novel electrodialysis, Environ. Sci. Technol. 47 (2013) 5888-5895.

[Zhang et al., 2011] Y. Zhang, K. Ghyselbrecht, B. Meesschaert, L. Pinoy, B. Van der Bruggen, Electrodialysis on RO concentrate to improve water recovery in wastewater reclamation, J. Membr. Sci. 378 (1) (2011) 101-110.

[Zhang et al., 2017] W. Zhang, M. Miao, J. Pan, A. Sotto, J. Shen, C. Gao, B. Van der Bruggen, Separation of divalent ions from seawater concentrate to enhance the purity of coarse salt by electrodialysis with monovalent-selective membranes, Desalination 411 (2017) 28-37.

[Zhang et al., 2012] Y. Zhang, S. Paepen, L. Pinoy, B. Meesschaert, B. Van der Bruggen, Selectrodialysis: fractionation of divalent ions from monovalent ions in a novel electrodialysis stack, Sep. Purif. Technol. 88 (2012) 191-201. 